\title{
Systems biology of cancer: entropy, disorder, and selection-driven evolution to independence, invasion and "swarm intelligence"
}

\author{
M. Tarabichi - A. Antoniou - M. Saiselet - J. M. Pita • \\ G. Andry • J. E. Dumont • V. Detours • C. Maenhaut \\ Published online: 25 April 2013 \\ (C) The Author(s) 2013. This article is published with open access at Springerlink.com
}

\begin{abstract}
Our knowledge of the biology of solid cancer has greatly progressed during the last few years, and many excellent reviews dealing with the various aspects of this biology have appeared. In the present review, we attempt to bring together these subjects in a general systems biology narrative. It starts from the roles of what we term entropy of signaling and noise in the initial oncogenic events, to the first major transition of tumorigenesis: the independence of the tumor cell and the switch in its physiology, i.e., from subservience to the organism to its own independent Darwinian evolution. The development after independence involves a constant dynamic reprogramming of the cells and the emergence of a sort of collective intelligence leading to invasion and metastasis and seldom to the ultimate acquisition of immortality through inter-individual infection. At each step, the probability of success is minimal to infinitesimal, but the number of cells possibly involved and the time scale account for the relatively high occurrence of tumorigenesis and metastasis in multicellular organisms.
\end{abstract}

Keywords Cancer $\cdot$ Systems biology $\cdot$ Entropy $\cdot$ Noise . Emergence

\author{
M. Tarabichi $\cdot$ A. Antoniou $\cdot$ M. Saiselet $\cdot$ J. M. Pita $\cdot$ \\ J. E. Dumont $(\square) \cdot V$. Detours $\cdot C$. Maenhaut \\ IRIBHM, Brussels, Belgium \\ e-mail: jedumont@ulb.ac.be \\ C. Maenhaut \\ WELBIO, Wallonia, Belgium \\ G. Andry \\ J. Bordet Institute, Université Libre de Bruxelles, \\ 1070 Brussels, Belgium
}

J. M. Pita

UIPM, Instituto Português de Oncologia de Lisboa Francisco

Gentil (IPOFG) and CEDOC, FCM,

Universidade Nova de Lisboa, 1169-056 Lisboa, Portugal

\section{Introduction}

A major transition in the evolution of life has been the passage from unicellular to pluricellular organisms. At this stage, each cell had to transfer its main imperatives (to survive and multiply) from itself to the organism, i.e., to subordinate them to those of the whole. The tumor cell accomplishes more or less completely the reversal of this transfer. In this review, we propose to analyze this inverse pathway. Transformations at any level of cell signaling may uncouple to some extent the tight subordination of a cell to the control of the whole. Over the long history of the organism, the sequential or simultaneous conjunction in cells of many such dysfunctions may lead in one cell to a transition to complete independence: the tumor cell. Some of these, the cancer cells, will evolve into an invasive, metastasizing state and eventually killing inside invader. From the point of view of these cells, the ultimate success is the transmission from one organism to another, i.e., the immortalization of the tumor by inter-organism infection. Besides, those who treat cancers often have the impression of dealing with an organism with its own strategy of survival. This reminds of the collective behavior of swarms of birds, fishes, or ants that, through a few simple reflexes, achieve coherent group behavior: the emergence.

In this assay, we try to present a tentative coherent narrative framework with known but often unrelated features of solid cancer evolution generally reviewed separately. In a systems biology approach, we consider mostly programs, pathways, and phenotypes rather than individual genes or enzymes used as examples. Many of the terms used in this literature are reviewed and defined in Ashworth et al. [1]. We based this review on important results from recent major journal publications. We shall consider, from the point of view of the cell, the causes of oncogenic events, which initiate the programs leading to the characteristic transition to independence of the tumor cell, then the evolution of tumors to cancers, metastases, 
and infectious cancers. We shall then discuss the concept of emergence of swarm-like behaviors in the progression of cancer. With regard to causes, we shall mainly consider phenomena more elusive than the direct classical viral or mutational carcinogens at the origin of a minority of cancers.

\section{Causal events}

\subsection{Propensity for disorder: entropy and its consequences}

What is entropy (cf. glossary)? Increasing entropy, the principle that, unless provided with new outside energy, any system will constantly lose usable energy, is a theoretical formulation for progressive irreversible disorder and randomness in the cells. The concept of entropy (structural genomic, transcriptomic, network of signal transduction, etc.) has been repeatedly applied to the characteristics of cancer tissue or cells: A role in the genesis of cancer was suggested [2-7], and a causal role was formally proposed in cancerogenesis $[8,9]$. This aspect will be emphasized in this review. Increased entropy of signaling (or gene interaction networks) has been well studied as a cancer characteristic: Network entropy (NE) increases along with cancer progresses, yielding $\mathrm{NE}_{\text {normal }}<\mathrm{NE}_{\text {tumor }}<\mathrm{NE}_{\text {metastasis }}[2,5]$. Examples of increasing disorder in the cell will be given in the next subsection. Increased entropy in cell signaling could result from any affected level: genetic, DNA damage repair, epigenetic, transcription control, mRNA editing, miRNA generation, translation, signaling pathways and cross-signaling, tissue structure, etc. [8]. In this regard, DNA damage repair, for example, can be seen as a gatekeeper for increased entropy of signaling, watching over the order in the DNA sequence.
The cell, as any other living system, degrades over time, but it repairs itself partially. It transforms by a phenomenon of graceful or fault-tolerant degradation. The known direct exogenous causes of cancer, X-ray or UV radiation, mutagen exposure, inflammation, etc., which can be thought of as extra-organism sources of disorder, are neutral or deleterious for part of affected cells and may kill them. But they may also in very few cells cause the activation of protooncogenes and inactivation of suppressor genes, leading them on the path to cancer. Similarly, the major part of signaling degradations and related mutations will have more neutral and deleterious than beneficial effects on the cells. Therefore, ultimately, they mostly lead to aging, senescence, and death by apoptosis or necrosis. But, among the few survivor cells with positive effects, only one suffices to initiate a cancer. Entropy of signaling can, in one cell, favor the appearance of oncogenic events in this cell, a competitive advantage and/or a greater probability of further changes, e.g., loss of negative control on cell proliferation. Further positive changes in these cells will further increase the competiveness and so on. The tumor cell will have accumulated enough advantages to become independent of normal physiological regulation (Fig. 1). The diversity of mutation combinations found from one cancer to another, in any type, is compatible with results of such an entropy-driven mechanism. The most classical, clinical, and experimental cancers studied are initiated by one well-defined oncogenic event such as protooncogene activation or tumor suppressor gene inactivation, which are also the very frequent common mutations of many cancers (the drivers in the initial cells) combined with many rare mutations specific for each cancer (passengers or enabling) [10]. Thus, study of genetic defects in human cancers has revealed for each cancer a few major causative genetic events (driving mutations) and

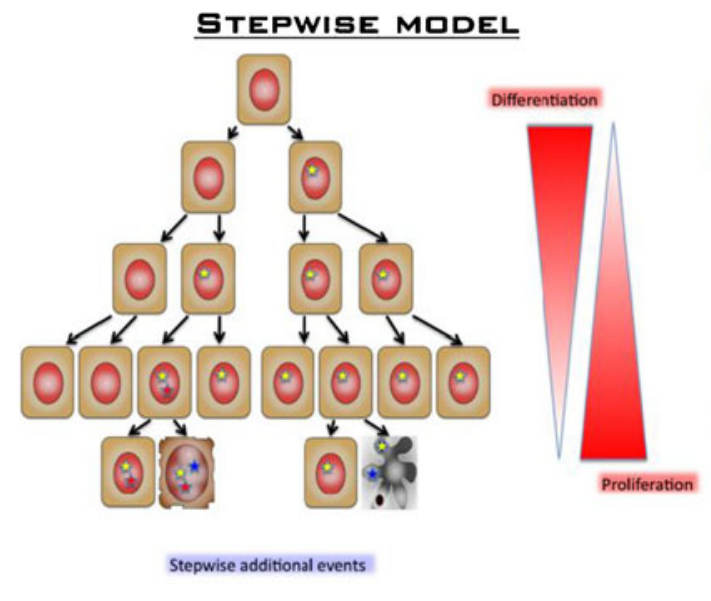

Fig. 1 The two extreme cases in the carcinogenetic transformation of a normal cell. Left: stepwise model in which sequential additional genetic events progressively lead to the fully developed, proliferative, and undifferentiated cancer cell (Vogelstein model). Right: catastrophic

\section{CATASTROPHIC MODEL}
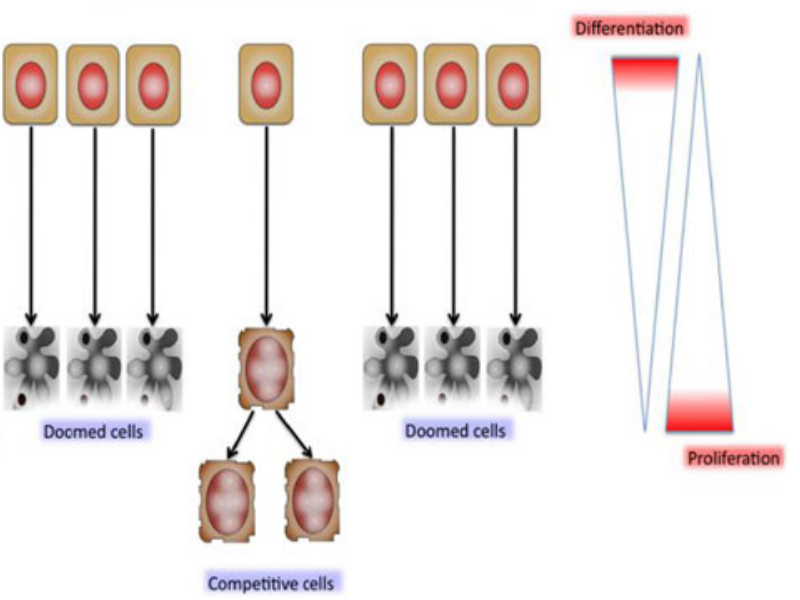

model in which a mitotic catastrophe (chromothripsis) or widespread mutations around a DNA repair site (kataegis) leads in one step to death of most cells and in one or a few cells to a cancer cell genotype. The two models might sequentially happen in the cells 
myriads of minor events, peculiar for each cancer. Whereas many of the minor events may be considered as mere passenger mutations, some are plural minor contributing events as illustrated by the many low penetrance polymorphisms linked to several types of cancer [11]. Thus, carcinogenesis could also result from a multitude of additional small genetic changes.

The five to ten driving mutations and hundreds passenger mutations in one tumor are observed in bulk tumor DNA, i.e., in the majority of tumor cells, which indicates a clonal origin [10]. Clonality is demonstrated for most, if perhaps not all, cancers [12]. This clonality indicates that, out of many combinations of stochastic events or changes of signaling, only one event combination has initially led to one tumor. It is not a whole population of cells that progressively became cancerous but one cell with the right combination of events. The derived cancer cells will bear the cancer-causing mutations but also all the random mutations acquired by the initiating cells before cancer initiation [13].

Cancer may also result from non-progressive acute causalities. Chromothripsis or chromoagenesis, the mitotic catastrophes caused by mitotic errors leading to widespread chromosomal rearrangements, induce the death of many target cells but also leads to aneuploidy, enhanced proliferation, and carcinogenesis of a few cells [14-16] (Fig. 1). In this case, it is not the accumulation of such effects but one major hot event that leads to cancer. Kataegis whereby point mutations rapidly occur in clusters over hundreds to million bases plays a similar role $[17,18]$. Viral oncogenes, radiation, carcinogenic agents, and inflammation may also lead to one major tumorigenic event.

Sequential combinations of stepwise and general catastrophic genetic events can also occur.

Regardless of the causing mechanism, if the initial carcinogenetic event bears only on somatic stem cells or pluripotent cells, it will have to occur in this minor fraction of the cell population, i.e., the number of potential initiating cells will be low. Whatever the fraction of the cell population involved, the more cells participate in the process, the greater are the chances that one becomes cancerous. Bigger breasts have higher cancer occurrence rate. On the other hand, dwarf mice (with impaired growth due to PTEN overexpression) are very resistant to cancer [19].

\subsection{Examples of increasing entropy in the cell}

Agents that hinder DNA replication often cause breaks in DNA [20, 21]. Transient MAP-2-induced chromosomal instability leads to lung tumor relapse after oncogene withdrawal [22]. Cryptic genetic variation, masked by the robustness of cell phenotype, may also represent an entropy-driven mechanism. It may have, in some circumstances, deleterious effects but in some others allow rapid evolutionary adaptation [23].
Clonal mosaicism (DNA changes) in subpopulations of cells of one individual increases with age and is suggested to be a risk factor for cancer [24, 25].

Aneuploidy resulting from faulty mitosis is a common cause of increased entropy of signaling in cancer. It is globally detrimental to cells, slows the rate of cell proliferation and organism growth [26], but, in a minority of cells, is associated with cell proliferation and thus frequently with cancer [27]. This tumorigenic effect is greatly increased when p53 is inactivated [28]. The most probable explanation for these are differences in gene dosage resulting from several mechanisms, genetic recombination, and defective DNA damage repair leading to gain of protooncogenes expression, loss of tumor suppressor genes, accumulation of improperly folded proteins, etc. This drives genomic instability and a mutator phenotype [27, 29].

Transcription-associated mutagenesis and recombination imply a direct relation between transcription rate and DNA damage [30]. This may explain in part the strong relation between division rate and malignity of cancers $[31,32]$.

Cells could be protected against minor protein structural defects by heat-shock proteins (HSP) (e.g., HSP90) [33]. Stochastic variations in the HSP expression can allow a minority of cells with protein defects to demonstrate a phenotype [34]. Diverse stress conditions lead to HSP transient inhibition and consequent aneuploidy [35]. Subtle variations in PTEN concentration and presumably other tumor suppressor genes predispose to breast tumors in mice [36].

Cancer cells themselves exhibit a less effective shield against disorder than normal cells, e.g., the disruption of euchromatin versus heterochromatin replication timing [37] transcription infidelity [38] and aneuploidy. Even in one breast cancer cell line, $1 \%$ of the mutations differ from cell to cell [39]. This will cause a faster evolution of tumors and a higher rate of cell death. On the other hand, transcription infidelity will generate mutated proteins that will elicit new antigenic sites and mild but definite antibody production [40].

Entropy also plays a role in cell biology models. In the generation of cell lines and in vitro evolution, signaling pathways which are separate and distinct in physiological differentiated cells become more and more interconnected in the derived cells (e.g., PCCl3, WRT, and FRTL5 rat thyroid cell lines) [41]. The final result of such evolution would be that almost everything does everything on everything [42]: an increased network entropy or a promiscuity of signaling which is the antithesis of tight physiological control.

\subsection{Noise as an alternative of entropy or a source to it}

Noise represents unavoidable spontaneous stochastic and reversible fluctuations from one moment to another or from one cell to another, of any variable (e.g., mRNA, protein, metabolite level, or structure). Such variations may be minor 
(a few percent) to very significant (whole or none). Noise functions in multicellular development, differentiation, and evolution by facilitating transitions [43]. It is expressed as stochastic bursts of expression, time averaging buffering the burst, propagation, and eventual amplification of fluctuations. Noise has an important role in genetic circuits and in the epigenetic landscape [44] by allowing some randomness in cell behavior [43]. Increased randomness in gene expression allows cells to better select for conditions best suited for a given situation [45].

Cell to cell variability and dynamics in the expression of key transcription factors [46] and at other levels [47] may allow very different responses of identical cells to changing conditions. Noisy splicing driving mRNA isoform diversity in human cells may play a similar role [48].

A consequence of the noise in cell processes is the very important functional heterogeneity at a given time of similar cells in the same conditions. For example, thyroid cells stimulated together with TSH responded, from one cell to another, with delays of minutes to $2 \mathrm{~h}$ by acute thyroid hormone secretion [49] or the timing of NFKB activation in 3T3 mammalian cells in culture submitted to the same stimulus TNF-alpha [50] is very different. Similar heterogeneity maintained by heritable epigenetic controls is an important element in malaria parasites and bacteria bet hedging $[51,52]$. This reversible heterogeneity in bacteria as well as in human cells may take place in time scales from seconds to days involving different mechanisms [53, 54]. It is believed to obey deterministic constrains [55].

Fine-tuning is one aspect of cell physiology that appears to be opposed to noise. Increasing noise increases the probability of escaping from existing regulatory constrains; decreasing noise decreases the possibilities of adaptation. On one hand, signaling circuits are robust to mutations and environmental fluctuations [56]. On the other hand, noise is extremely difficult to completely suppress [57]. Whereas noise is reversible and can decrease, entropy, which is cumulative, always increases. Increase of entropy will lead to progressive incremental changes, but a fluctuation may lead to a sudden qualitative change, a binary pattern which just requires a positive feedback to occur [53]. This could cause an irreversible change, potentially oncogenic.

Robustness is the capacity of a system to resist changes. It could be considered as a shield against entropy and noise [56]. Whatever its involved mechanisms, increased robustness of human cells could account for the requirement of more mutations to generate cancers in humans than in mice [58]. One example of the role of noise dampening by negative feedback as a protection against uncontrolled cell growth is the activation of p53 after a short mitogenic stimulus [59] preventing cell cycle entry.

Paradoxically, while robustness characteristics may protect normal cells against transformation, they may also at the tumor stage protect the cancer properties or oncogenes (e.g., oncogenic Raf stabilized by HSP90) [60].

\subsection{Role of miRNA in the control of noise and entropy}

A major mechanism of robustness is the redundant control by miRNA [61, 62]. miRNA controls are partial and multidimensional; one miRNA has several mRNA targets, and each mRNA has several controlling miRNA. miRNAs are fine-tuners of the cell biology (canalization) [63-65]. miRNA can therefore be considered as ideal guardians against increased entropy: Their moderate and combinatorial action is better suited to fine quantitative adjustment than to qualitative regulation. Their ascribed long half life is also suited to long-term adjustment and to robustness of a system [66]. The role of miRNA against increasing entropy is beautifully illustrated by the very progressive dedifferentiation and loss of tissue structure of mice thyroids in which Dicer gene, coding for the miRNA generating protein, has been inactivated (KO) [67]. A role of some miRNA in limiting the cellular response to E2F activation and thus preventing replicative stress is another example of such fine-tuning negative feedback [68]. The general role of miRNA downregulation in cancer has already been reviewed $[69,70]$. It is remarkable that general defects in miRNA synthesis progressively lead to transformation and tumorigenesis [71, 72]. General miRNA concentration decreases in cancer, and there are many defects at various steps of miRNA synthesis in many cancers [73], mostly by epigenetic silencing [74]. Most miRNA are downregulated in tumors, and low levels of miRNA-processing proteins (Dicer or Drosha) have been associated with the severity of several cancers [71, 75]. Also in breast tumor cell lines and breast cancer, a broad set of miRNA are repressed under estrogen proliferation treatment [76]. This general concept should not mask the fact that a minority of miRNAs could be causal agents of tumors [77]. However, loss of Dicer and the consequent depletion of miRNAs do not preclude tumor formation by a sarcoma cell line [78].

Although little is known on the subject, entropic alterations of ncRNA could play the same role as those affecting the miRNAs.

\subsection{Relation of entropy to aging}

Aging of an organism can be defined as the progressive decline and deterioration accompanying age. Entropy and aging are strongly related, as aging is the major consequence of increasing entropy. Gene network integrity declines with age in Caenorhabditis elegans [79]. In nucleotide excision repair disorders, there is a striking correlation between the degree of repair deficiency, aging, and cancer [80]. Analysis of 27 datasets of tissue gene expression in aging mice, rats, 
and humans demonstrates over-expression signatures of inflammation, immune response, apoptosis, and senescence [81]. Aging mice have increased chromosomal instability and cancer [82]. The aging process thus impairs all cells and increases the probability of cancers in some.

\section{Transition to independence (Fig. 2)}

The definite transition from a normal cell to a tumor cell is a fundamental change of philosophy: The cell and its descendants no longer behave as functional components of the organism submitted to the physiologically perceived requirements of the whole [83]; it becomes independent as a unicellular organism applying to itself and its descendants the ultimate rules of such an organism: to survive and multiply [84]. It is a reversal of the fundamental transition from unicellular to pluricellular organisms. Many of the genes associated in processes of metazoan multicellularity are also implicated in cancer [85].

The asociality of tumor cells even goes as far as ingesting and digesting other tumor cells or even lymphocytes [86, 87]. This transition, as well as the further steps in the evolution of the tumor $[17,18]$, may occur stepwise, as in the Vogelstein model, or at once, e.g., after chromothripsis [14], kataegis, or in a sequential combination.

When progressive, the evolution of tumor cells involves several major steps: the independence of growth of the cells (tumor cells) in a benign tumor, the evolution of the tumor cell to cancer cell, the process of invasion and epithelialmesenchymal transition (EMT), the metastatic process with its own various steps, and ultimately inter-organism transfer. Several steps can occur at the same time.

In two landmarks articles synthesizing a huge amount of information on cancer, Hanahan and Weinberg [84, 88] outlined the few general properties (hallmarks) that cells must acquire to become cancerous. In fact, one can interpret some of these properties as the relief of constrains that subordinate the normal cells of a pluricellular organism to the physiological requirements of the whole. Two of these hallmarks are the prerequisite for the first step of tumorigenesis, i.e., independence: (1) sustaining proliferation signaling: It involves proliferation as a unicellular organism, without need of initiation by a physiological growth factor, and evading of growth suppressors and loss of contact inhibition [89]; (2) activating invasion involves the relief of physiological tissue constrains, cell-cell adhesion, polarity, anoikis, etc. This relief, which may involve genetic or epigenetic events [90], is also described as field cancerization [91]. It is therefore interesting that the Warburg type of glucose channeling into non-oxidative metabolism confers resistance to anoikis [92].

Sustained proliferation and invasion are together sufficient to initiate a tumor. Both are necessary: If repressed, there is no tumor. For example, cancer cells in a normal tissue matrix in vitro may not proliferate [93, 94], and cancer cells inserted in a morula may differentiate in the resulting organism as perfectly normal cells [95]. When mammary cells are cultured in a tissue-like environment, isolated cells expressing one of the most classical oncogenes (ERBB2) fail to develop and proliferate. Only by moving cells out of tissue constrains does ERBB2 allow cell transformation. The negative constrains of pluricellular organisms dominate
Fig. 2 The first phase of progressive transformation of an epithelium to an independent tumor: loss of proliferation constrains and loss of tissue constrains in any order

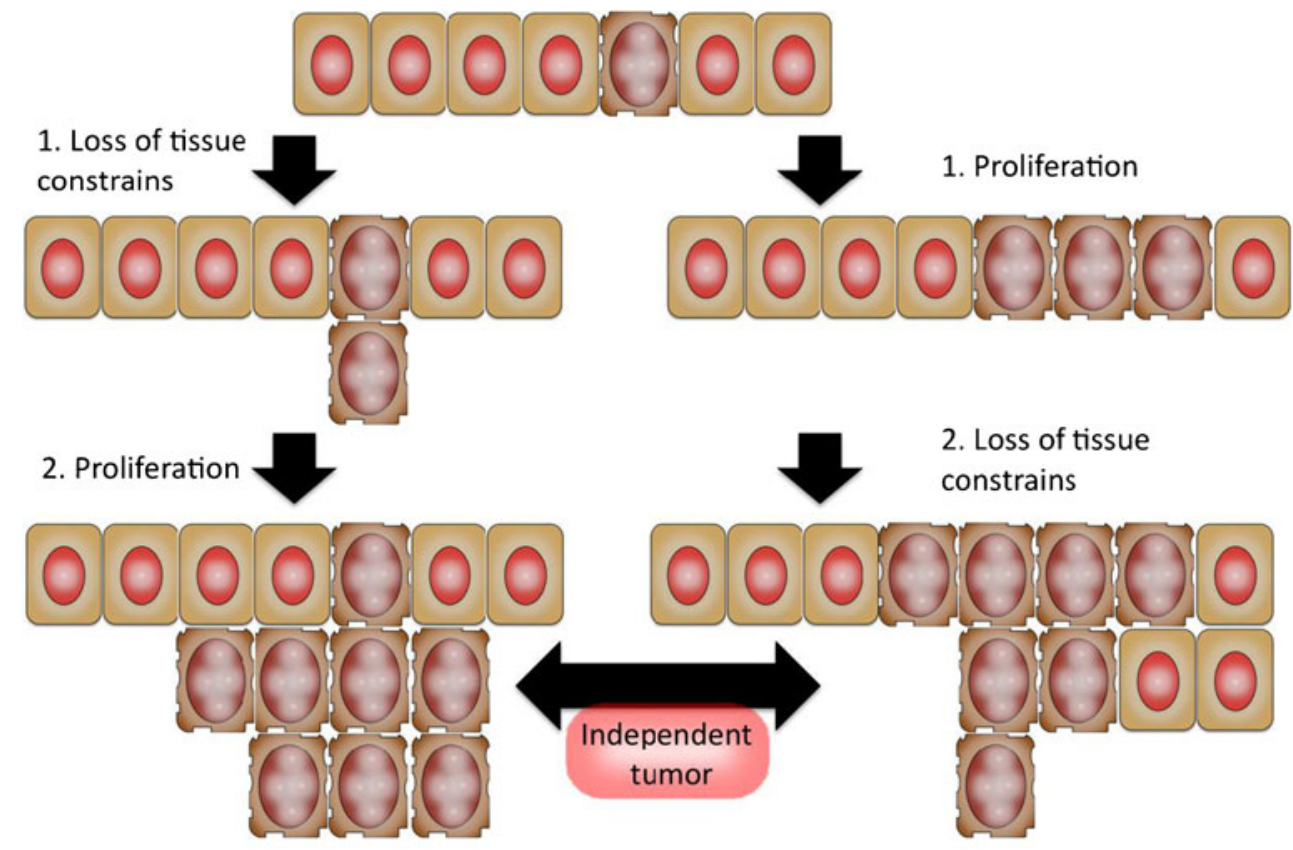


[96]. Loss of epithelial tissue constrains may follow inactivation of protein(s) involved in tissue organization, e.g., in gap junctions [97], in tight junctions [98], PAR1 kinase [99], or in cell substratum adhesion (e.g., by metalloproteases) [100]. However, loosening of cell compartmentalization, which is part of the invasion process, is a necessary but not sufficient carcinogenetic event. Most normal epithelial cells die when dissociated from the epithelium. The mechanisms of loss of epithelial cell organization and of escape from its lethal consequences are complex and have become a major research subject [101].

Independent growth induced by cell endogenous oncogene or loss of tumor suppressor gene is the second and best recognized requirement for independent growth. However, this characteristic is often accompanied by several negative effects and feedbacks, which must be overcome. Their mechanisms are multiple and therefore difficult to bypass. They include: oncogenic induced apoptosis, i.e., suicide (e.g., Raf-induced apoptosis), oncogenic-induced senescence, DNA damage induced arrest of cell cycle (checkpoint G1, Gs, G2), or catastrophic mitosis and post-mitotic cell death. Thus, even at this stage, a high proportion of early tumors will fizzle out (e.g., in experimental skin tumors) [102].

The other hallmarks leading to further transition to cancer may be acquired later in the evolution of the tumor. For instance, differentiation characteristics are lost progressively with the aggressiveness of thyroid tumors [103]. In the case of progressive cancerization, the cumulative probability over time for a given cell of having accumulated the necessary complementary events and the consequent hallmarks will increase, along with the growth of cancer incidence with age [104].

Competition as such is a characteristic of tumor cell populations, but it also occurs in normal tissue. If independence is the first necessary step in tumorigenesis, cell-cell competition is not sufficient. Competitive interactions between cells in a compartment or between stem cells in a niche, already select, better endowed, more competitive winner cells and their descendants $[105,106]$. This represents a physiological mechanism of selection. Live cell delamination, followed by cell death, is a physiological mechanism which counterbalances epithelial growth and limits tissue overcrowding [107, 108]. Cell competition, with losers going into apoptosis and winners generating descendants which replace them, exists in non-tumoral conditions with mechanisms generating supercompetitors (e.g., Myc over-expression) and mechanisms protecting for a while losers from apoptosis (transient Sparc expression during development in Drosophila) [109]. A p53inactivating mutation in bronchial epithelium allowed descendent cells to spread in $70 \%$ of the mucosa [110] without generating a cancer. Loss of polarity in Drosophila wing leads to apoptosis and compensatory proliferation [46]. Impairment or the mere heterozygosity of the basolateral membrane organizer SCRIB is sufficient to initiate prostate hyperplasia and further biallelic loss [111].

Tissue constrains exerted through polarity, tight, and adherens junctions restricting cell proliferation are often mediated by the Hippo pathway [112]. This pathway may even eliminate deviant tumor cells generated by inactivating mutations of tumor suppressor genes [113, 114]. The Hippo and the TOR pathways regulate the control of normal organ size in opposite direction [112, 115].

\section{Evolution from independence to cancer (Fig. 3)}

\subsection{Mechanisms}

Once having acquired its independence, the tumor may progress or not by successive additional steps to acquire all the hallmarks of cancers and to develop the competitiveness of its cells [116]. It could also acquire all these properties at once in a few cells after a catastrophic genome rearrangement (e.g., chromothripsis, kataegis ...). We shall mainly consider the progressive model.

"Tumors evolve by a reiterative process of clonal expansion, genetic diversification and clonal selection within the adaptive landscapes of tissue ecosystems. The dynamics are complex with highly variable patterns of genetic diversity and resulting multiclonal architecture" [117-120]. The process is favored by the mutator phenotype of cancer cells [121], with the mutation rate increasing in more advanced stages [18].

The role of the DNA damage response as an anticancer barrier in early tumorigenesis suggests that new genomic instability is an early phenomenon after independence [122] and contributes to evolution. Among the genetic events, some like those affecting genes of the splicing machinery are frequent and may influence entire programs [123]. The mutations may also involve recurrent hemizygous, sometimes extensive, deletions [124]. The reprogramming of characteristics is therefore largely a result of the reprogramming of the genome itself with the emergence of new genomic systems [125]. Clonal evolution of tumors (e.g., in leukemia) in response to treatment has been demonstrated by whole genome sequencing [126].

This evolution also involves epigenetic and possibly lysogenic-like and transcriptional control mechanisms [40, $127,128]$. In colon cancers, epigenetic events are far more frequent than genetic events [129], and in lung cancer, they may account for the regression of most differentiation genes [130]. Transcriptional networks, which are able to maintain 
Fig. 3 Schematic view of steps in tumor evolution. From one normal cell, to dominance of this cell, independent benign tumor, invasive tumor, cancer, and metastasis. The width of the arrows suggests the relative importance of the relations

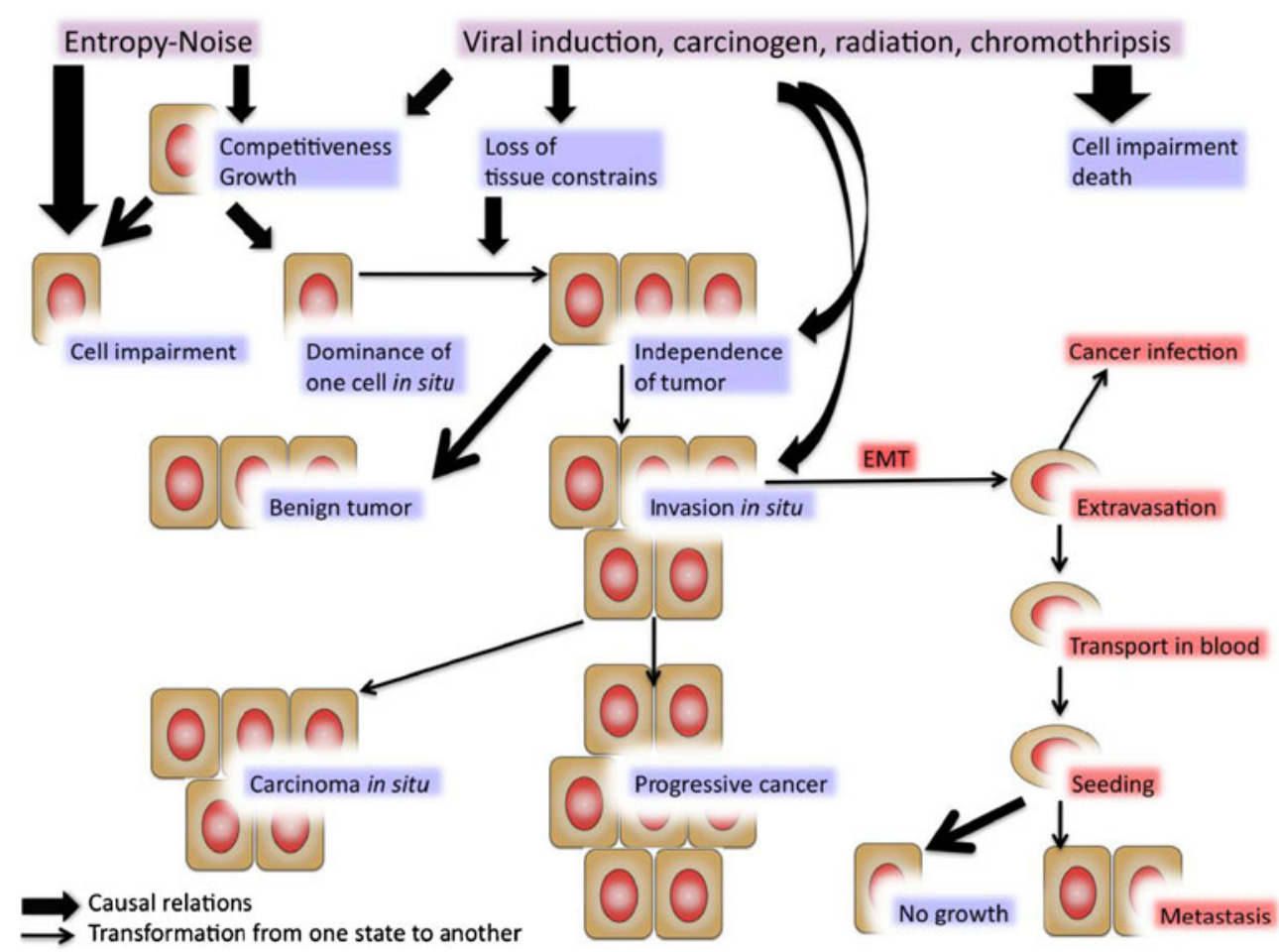

cellular identity, certainly also have the capacity to play a major role in cancer cell identity [131].

The Darwinian selection will eliminate many less competitive clones [132]. The cells will lose physiological characteristics (i.e., differentiation) that are unnecessary for their survival and reproduction, if not all characteristics of the cell of origin, some of which being used in the new context. The end result is a great diversity and heterogeneity [133, 134]. Examples are the greatly increased mRNA heterogeneity in cancers [38] and the great diversity of single-nucleotide mutations from cell to cell in a cancer [135-137]. Cancerization is not a linear process either in space or in time.

Just the fact that cancer cells proliferate, vary epigenetically, and mutate allows them to discover myriads strategies to escape attacks by anticancer drugs [138, 139]. Noise increases the adaptability in the cancer cell population. Similarly, the faster increasing entropy of cancer cells, e.g., in chromatin replication timing [140], favors the appearance of new mutations, allowing some cells to resist therapies based on existing oncogenic mutations [141]. For example, treatment of B-Raf mutated melanoma selects cells with Ras mutations which will short-circuit the inhibition and re-establish the activation of MAP kinases in the tumor and also in normal cells, thus generating new skin carcinoma [142]. Treatment of cells of an osteosarcoma cell line by nutlin which blocks p53 degradation leads to somatic inactivating mutation of $\mathrm{p} 53$ and selects for $\mathrm{p} 53$ mutated cells [143]. Inhibition or lack of telomerase activity in human cancers leads to alternative lengthening of telomeres mechanisms [144]. An analogy between the evolution of drug resistance in bacterial communities and malignant tissue has been suggested [145].

On the other hand, some mutations or epigenetic controls while not being beneficial or detrimental per se might introduce a new vulnerability to treatment [146, 147].

Moreover, the process of adaptation by mutation is not necessarily infinite, e.g., in bacteria diminishing returns of epistasis among beneficial mutations decelerates adaptation [148] and lead to an equilibrium of maximal efficiency.

The pervasive increasing entropy in tumor cell evolution will, as in the normal cells, generate far more deleterious than favorable genetic and epigenetic events. This will lead to the development of much more uncompetitive than competitive cells. Tubiana had demonstrated this [149]: Only 10 to $20 \%$ divisions in breast cancer cells contribute to tumor growth. The less competitive cells may divide a few times but not infinitely, redifferentiate, and become senescent, quiescent, or even die. The other, more competitive cells may correspond to the so-called cancer stem cells postulated by the cancer stem cell theory that we called cancer stem-tumor-propagating cells [132]. These cells, defined by different sets of properties depending on the systems and the authors, need not be a fixed distinct population of cells, but rather one extreme phenotype in an evolving population $[132,150,151]$.

Thus, the same increase in entropy that generated initially the tumor-initiating cell will impair many cells during the evolution of the tumor but allows new adaptations to arise in a minority.

Due to the stochastic nature of genetic events and their relation with cell divisions it is not astonishing that the best 
prognostic markers of tumor evolution are the Ki67 proliferative index and tumor size $[31,32]$. The more cell divisions, the more cells involved, and the more mutations, a fraction of which will contribute in the affected cells to positive tumor cell evolution.

\subsection{Features of the evolution}

Besides the properties acquired in the first transition to independence, mobility, autonomy, and escape of tissue constrains, what are the properties progressively acquired by tumor cells in their evolution to cancer cells, the hallmarks of cancer [84]?

These properties include the capacity to react independently to the environment (e.g., $\mathrm{O}_{2}$ availability, signals from other cells), loss of differentiation, the search for $\mathrm{O}_{2}$ and substrates; movement, propagation, and exploration behavior; proliferation whenever, wherever it is possible; escape harmful conditions and environment; escape immune reactions; escape of metabolic control; and escape of apoptosis. These correspond to the imperatives of the cancer cell progression and invasion. At the step of invasion, the tumor has acquired the full set of cancer properties, and it is a required step for metastasis. Tumor cells may migrate in bulk as clusters, strands, or sheets (collective migration) or individually. In the latter case, they may, after EMT, either proceed through the extracellular matrix by hydrolyzing and remodeling it or may swim around it as an amoeba [152]. These patterns are reversible depending on the context (e.g., extracellular matrix organization).

The newly acquired properties are not independent; they all reflect the new character of the cell: its cancerishness. A nice illustration of this is the finding that all proposed specific gene expression signatures of breast cancers are related and therefore give redundant prognostic results [32]. The programs and their resulting hallmarks represent a complex interrelated dynamic network in which some hallmarks themselves drive new programs. In this regard, the Warburg reorganization of cell metabolism in cancer is both a consequence and a cause of the cancer process itself [153-155]. The Warburg effect confers resistance to anoikis [92]. The invasion programs imply a close and reciprocal interrelation with the extracellular matrix and the various micro-environmental cancer and non-cancer cells. They present a great variety. The dynamic interrelations of the hallmarks are also illustrated by the many mechanisms of immune escape. Cancer vaccination drives Nanogdependent evolution of tumor cells toward an immuneresistant and stem-like phenotype [156]. Hypoxia induces escape from innate immunity through HIF and Adam10 [157] and promotes tolerance via Treg cells [158]. Lactate as such stimulates migration, radioresistance, and immune escape [159]. A large part of the program of embryonic stem cells taken over by cancer cells is the prevention of differentiation.

The evolution of the independent tumor to cancer will involve the acquisition, progressively (evolution) or abruptly (e.g., after chromothripsis), of all those properties, not necessarily in a given sequence. At any step, the progression of a tumor clone may stop, but this will have little general effects at stages when many clones coexist. Also, higher saturation density is increasingly permissive for expression of the neoplastic transformation [94].

This evolution will involve the acquisition of all these properties leading to tumor growth, the required angiogenesis, invasion, and ultimately metastasis. Exaggerated angiogenesis will increase but also restrain tumor access and become a pathological process per se [160]. The evolution will result from branched genetic evolution within the tumor [134] as well as even more frequent epigenetic changes [161-163].

For this evolution, the cells will transiently or permanently appropriate programs that improve their competitiveness and growth. The over-expression by human cancers of genes that are specific to a variety of normal human tissues [164] may reflect this adaptation or/and the increasing entropy of cancer cells. Most often, cancer cells do not invent new programs; they co-opt or highjack available programs expressed in some circumstances by certain cells such as, for invasion, the wound program [165]; for growth, the regrowth program of amputated liver; for adaptation, to flux the program of blood cells; for escape of differentiation constrains, programs of embryonic stem cells, etc. One other example is the appropriation of leukocytic trafficking and leukocyte attraction mechanisms for invasion and metastasis [166]. To provide itself with the necessary building blocks for proliferation, the cancer cell activates permanently a temporary program of the normal cell cycle [167], thus generating a permanent Warburg effect [168].

Versatility in the use of such programs confers to the cell a nimbleness that reminds of the embryonic cells. For instance, cMyc oncogene when expressed induces proliferation but suppresses cancer metastasis [169], i.e., negative and positive roles played by over-expressing the same protein.

In a given cancer, there is complementarity, a synergy between amplified and mutated genes in eliciting programs [170]. Many cells need an active PI3K pathway to grow, and when they have no activating mutation of the pathway, they over-express IGF1 receptors [162]. When the pathway is inhibited by therapy, recurrences make use of a Met or cMyc amplification [171]. Similarly, the widespread potential of cancers to adapt to treatment may involve the redundancy of growth factor-regulated signaling cascade [172], heterodimeric activations [173], emergence of new mutations [174], etc.

The respective use of all these programs varies for different cancers and for one cancer at different times and 
locations, depending on the existing conditions and the cells accessible programs [175]. For instance, telomere dysfunction in the absence of telomerase generates very disadvantageous genomic instability but is often corrected by reexpression of telomerase [126]. EMT transition can suppress major attributes of human epithelial tumor-initiating cells [176]. Plasticity, reciprocity, and evolution are the major characteristics of these processes $[175,177]$.

The evolution of cancer toward independent and maximal growth, and loss of differentiation characteristics leads to a convergence of phenotypes between cancers of same type with very different genotypes [178] and even between different cancer types [178, 179], especially for the most dedifferentiated cancers. However, the programs used will often still reflect characteristics of the cell of origin, which are useful for their progression. For instance, transcription factor TTF1 (also called NKX2.1), which is used and necessary in thyroid and lung normal cells proliferation is still used and necessary for pulmonary and thyroid cancer cell lines growth [180].

Not all cancers use all available programs. For instance, basocellular skin carcinoma or brain tumors may not express EMT program nor develop metastasis. Also, not all the cancer cells in a cancer express the same programs, nor do they necessarily express them all the time, e.g., EMT is induced in some peripheral carcinoma cells and is reversible after metastasis [181].

A step of the evolutionary process is the development of the cancer independently of its initial cause, e.g., the skin tumor in response to a mutagenic then progression treatment, which develops independently of the causal oncogenic events thereafter. By contrast, a hyperplastic tumor may develop with a hormonal treatment or with the expression of an oncogene, both of which recede when the stimulus is stopped [182]. In the first case, the tumor cells have acquired an independent property, but, in the other, did not. Oncogenic addiction, the necessary activity of one oncogene for tumor progression characterizes this latter type. Because of its mechanistic simplicity and economy, it is very efficient but offers simple therapeutic targets. The inverse, oncogenic independence may arise following treatment (e.g., by relief of a negative feedback on EGFR in Raf-induced melanoma) $[183,184]$. It explains some resistances to single target treatments. Non-oncogene addiction may also occur, for example, to heat-shock factors that compensate for protein denaturing stress resulting from the increasing entropy of cancer cells $[124,185]$.

The classical scenario of tumor progression to cancer described so far should not obscure the fact that many tumors do not progress or even regress. This is a well-recognized possible fate of benign tumors such as hemangiomas, lymphangiomas, gliomas, etc. Thyroid microcarcinomas, with all the characteristic of classical papillary carcinomas (e.g., B Raf mutations, RET-PTC rearrangements), are found in up to $30 \%$ systematic autopsies. Most never evolve [186]. Similarly, naevi may be considered as dormant quiescent melanoma [187]. There are many dormant breast carcinomas [188], prostatic intraepithelial neoplasia [189]. Mechanisms of these evolutions are poorly reversible senescence [189] which may result from the uncorrected oncogenic stimulus itself [189] or the control by T cell infiltration [190].

\section{Metastasis program}

The generation of metastases is a third step in the evolution of a cancer. It is most important and lethal since it is responsible of $90 \%$ of cancer deaths worldwide.

As shown by mutation patterns of tumors and metastases, metastases can be generated early from the bulk of the tumor as well as late in its evolution from some cells in the tumor [191]. A lot of arguments in favor of each concept show that both are valid. However, the rarity in the primary tumor of clonal genetic events found in metastasis suggests that only rare cells in this tumor have the ability to metastasize [192]. The genealogy of metastases shows that some are early, some are late, and some are even metastases of metastases [193]. Moreover, there are metastases of undetected cancers [194]. Thus, the metastasis program can be independent of other cancer cell programs.

The steps involved in the metastasis process have been analyzed [195, 196]. They include invasion, individualization or not of the cells by EMT, migration toward capillaries, intravasation, survival in circulation, extravasation, seeding, and growth as metastasis. EMT which ultimately individualizes the cells, which then acquire a mesenchymal type, implies the loss of cell-cell adhesion and cadherins and a switch of the cytoskeleton proteins from cytokeratins to vimentin $[93,152]$. It is a major determinant of metastasis [197].

Each metastasis step implies different capacities and programs and a certain frequency of failures. After EMT, extravasation of the cells is certainly facilitated by their attraction to oxygen and by the large but tortuous and leaky vascularization of the tumor [198]. Moreover, cancer cells, by decreasing stiffness and increasing cytoskeletal remodeling of endothelial cells, break down the endothelial barrier [199]. Survival in the circulation certainly requires the hallmark characteristic of escape from anoikis, the apoptosis of cells that lost cell contact.

According to Valastyan [195], once in circulation, survival, extravasation, and seeding are very efficient. Eighty percent of intravenously implanted carcinoma cells succeed in extravasation. These steps do not even require malignancy of the cells as normal mammary cells succeed to achieve 
seeding if not growth [200]. On the other hand, the attrition rate for metastases is evaluated at $99.98 \%$, i.e., a success rate of $2 / 10^{4}$ [201]. As it is difficult to imagine a significant evolution in the few hours or days between intravasation and seeding, either the necessary capacities for metastatic development are stochastically available in a fraction of the intravasating cells or they are acquired in some cells later after seeding. The major limiting factor is the tissue environment, i.e., in part, the composition of extracellular matrix, the niche [202]. Also, the cancer cell may exploit for its implantation surface proteins expressed by chance, e.g., claudin-2-expressing breast cancer cells functioning as unspecialized adhesion molecules to bind breast cancer cells to hepatocytes [203]. Additionally, primary tumor-associated stromal cells can also be seeded in secondary sites and potentiate the metastases formation [204].

It is easy to explain metastases of peripheral organs in the lung where venous blood from the tumor will have to pass, or metastases of visceral organs in the liver where most of their venous blood passes. It is more difficult to conceive how groups of cells of a diameter from 10 to $30 \mu \mathrm{m}$ can escape the filters represented by the capillaries of lung and liver. However, there are venous shunts in the lung, which allow less than $1 \%$ of the circulating blood to bypass lung capillaries. The necessity of intravenous shunts to bypass liver and lung would imply a great attrition rate at this level. On the other hand, isolated cancer cells, the present favored origin of metastases [205], could flow through the capillaries, as the leukocytes do. In fact, such cells also hijack other leukocyte programs, e.g., for extravasation [166].

Choice of the metastatic site, the organ-specific metastatic tropism, will be conditioned by the environment (e.g., cytokines, etc.) and by the adaptation of the seeded cells to their environment. Those breast cancer cells that succeed to colonize the lung are those which produce tenascin as a metastatic niche complement [202].

The stochastic character of the transition of cancer cells to metastasis is illustrated by the nice relation between size of tumor and number of metastases [149].

The ultimate step in the evolution to total independence of cancer cells is the success of some cancers to transfer from one organism to another, as parasites do: by infection like Tasmanian devils transmissible tumors, which in their path to total independence have even managed to acquire new mitochondria from one transitory host [206]. This cancer has now evolved in several subclones sufficiently different to evade immunity against one of them [207]. Canine transmissible venereal tumor is another example [208, 209]. Other examples of interorganism transfer are the cases of maternal transmission to offspring [210], fetus to fetus transmission [211], and transmission with organ transplants [212].

\section{Cooperation, "swarm intelligence," and "emergence" in cancer}

What is emergence (cf. glossary)? To the clinician who treats it, cancer often appears as an intelligent enemy, displaying what is known as swarm intelligence. Swarm intelligence refers to the collective behaviors of a decentralized selforganized system composed of single individuals interacting locally by few signals. It is also called collective intelligence or said to display an emergent property. The interactions between the single entities are stochastic. The equilibrium reached by the whole population is dynamic. In that context, emergence is the generation of swarm intelligence in a collection of such individuals. It must result from the acquisition by Darwinian selection of the appropriate reflexes by the whole population. It is therefore a biological concept $[213,214]$. Common examples are flocks of migrating birds, of fishes, ant colonies, soil microbes [166], and perhaps packs of cars at the beginning of vacation. In emergence, the different units of an entity display teleonomic, i.e., apparently purposeful behavior [215].

Normal cells display cooperation. Bacteria use few signals and stereotyped responses to cooperate once their density is sufficient (quorum sensing), to develop swarming behavior, luminescence, and other cooperative behaviors [216]. Animal gene regulatory networks by themselves generate emerging properties [217]. The major process of invasion, the collective tumor cell invasion, involves concepts of cell-cell cooperation and collective behavior [205] programs appropriated from embryological development [214].

The complex interplay between genetically distinct populations within a cancer has already been discussed with examples of commensalism (i.e., positive interaction where one clone benefits the others) and mutualism (cooperation between populations) [1].

Hypoxia and angiogenesis represent one striking example of "intelligent cooperation." The response to hypoxia is a remarkable general response of the tumor cells to a deleterious condition, with cells moving toward oxygen and vessels, becoming more malignant, etc. In fact, tumor vessels' therapeutic targeting promotes adaptations in cancer that result in increased malignancy [218].

Hypoxia and HIF $1 \alpha$ induce aggressive growth, invasion, angiogenesis, and metastasis in xenografts of human cancers [219], zebrafish tumors [220], and pancreatic cancer cells [221]. The activation of HIF leads to the induction of SNAIL transcription factors conferring EMT and stem cell properties [222] and of transcription factors such as OCT4 conferring stemness properties [223], telomerase, and multidrug transporters. Hypoxia and HIF also promote VEGF secretion and angiogenesis and activate an invasive program by upregulating Met tyrosine kinase [224]. Similarly, lactate levels predict likelihood of metastasis and tumor 
recurrence in human cervical cancers [225]. The shift to glycolysis from glucose oxidation (Warburg effect) protects cells from anoikis after detachment [92]. Some glioblastoma cells even generate endothelial cells and vessels themselves which irrigate the tumor $[21,226]$. Thus, hypoxia and HIF induction, early consequences of the process of tumorigenesis, are major drivers of this process [227].

Cancer invasion potential and resistance to therapy are interconnected properties, more or less linked programs that may induce each other [228].

Another example of cooperative collective behavior is illustrated by the tumoral control of the microenvironment. In the invasion process, there is a reciprocal reprogramming of both tumor cells and the surrounding tissue [177]. For example, the breast cancer-associated fibroblasts which induce EMT and chemoresistance [229], stromal fibroblasts surrounding cancer cells, may stretch out in parallel networks letting cancer cells move along them [230]. Tumors may secrete PDGF-BB to stimulate stromal cells to produce erythropoietin which induces angiogenesis and red cell generation, i.e., which improves their oxygen supply [231]. They also recruit mesenchymal stem cells which stimulate growth, metastasis, and resistance to cisplatin [232] and which supply them with cysteine, allowing them to synthesize the necessary glutathione [233]. On the other hand, of course cancer cells compete with normal cells. A role of secretory miRNA of tumoral cells has been proposed in this regard [234].

In experimental models, cooperation may also involve different tumor cells with complementary mutations (e.g., Ras V12 and SCRIB-mutations [192]. Even senescent cancer cells may harness wound healing responses to support the other cancer cells [235].

Inflammation is another cooperative phenomenon. Its role is illustrated by the remarkable slowing down of tumor progression by aspirin treatment [236]. Recognition of tumor-specific antigens by lymphocytes leads to cancer immunoediting, loss of tumor antigen expression or presentation in some cells that will then selectively outgrow the others [237], secretion of immunosuppressive cytokines, lymphocytic inhibitory enzymes (e.g., indoleamine 2,3 dioxygenase), or recruitment of immunosuppressive Treg cells [238]. Tumor acid $\mathrm{pH}$ inhibits $\mathrm{T}$ cell immunity [239]. Clearance of apoptotic cells, very frequent in cancers, results in the production of anti-inflammatory cytokines [240]. On the other hand, acquisition by melanoma and colon cancer cells of chemokine receptors $(\mathrm{CXCl} 3, \mathrm{CXCR} 1$, CCR7), which in lymphocytes attract the cells to lymph nodes, will lead these cancer cells to lymph node invasion [241].

Cooperation may also be observed as response to therapy. During cancer radiotherapy, tumor cells dying from apoptosis stimulate growth and repopulation of the tumor [242].
Danger signals produced by irradiated tissues also comprise pro-angiogenic molecules, thus protecting the vasculature [243].

An even more daring but still to be substantiated theory would have the cancer-cell-secreting factors that would mobilize bone marrow-derived cells to pre-metastatic sites [244]. Another hypothesis is the transmission of neoplastic properties from transformed to normal human stem cells [245].

All these examples of cell cooperation could represent true emergence, i.e., a collective behavior resulting from reflexes of signaling acquired by a Darwinian selection.

The evolution from drug-sensitive to insensitive cells does not fall into the emergence category as it reflects rescuing mutations in a few cells that take over and regenerate a whole population [246].

\section{Efficiency of the cancer process}

Although collectively, cancer cells are deadly, at the level of the individual cells, the carcinogenetic process is remarkably inefficient. At each step of the cascade, the frequency of events deleterious to the cell outnumbers the frequency of positive evolutionary events, but these generate the progression. In mammary cancers, up to $90 \%$ of the cells are doomed [149]. The cancer stem-tumor-propagating cells concept, with only a fraction of the cancer cells being competitive, implies the same conclusion [132].

At each step of the cascade, especially in the early steps, the lack of a supplementary event may stop the process in its track. This explains the high frequency of benign or static tumors (e.g., cancer in situ). At each step of the cascade, tumors can even regress if they have not achieved immortality (e.g., hemangioma). However, at the end of the evolutionary process, one cell is sufficient to generate a xenotransplanted mammary tumor [247].

A gross estimate of cell number at different stages of thyroid cancer evolution gives an appreciation of the efficiency of cancerization from the point of view of the cell. One thyroid $\left(3 \times 10^{9}\right.$ cells $)$ with $7 \%$ annual renewal [248] over 30 years generates one or two nodules in $50 \%$ of the female population, (probability $1 / 10^{10}$ per cell) of which $5 \%$ are malignant (probability $5 \times 10^{-12}$ per cell). At another level, a cancer of $1 \mathrm{~g}\left( \pm 5 \times 10^{8}\right.$ cells $)$ releasing in the blood 50.000 cells per day or $2 \times 10^{7}$ cells per year, generating five metastases in 5 years, represents a probability of $5 \times 10^{-8}$ metastasis per released cancer cell. Even for a release of 500 cells/day, the probability would be $1 \times 10^{-6}$. Finally, only two cells in history, the Tasmanian devil and the canine transmissible venereal tumor cancer cell, managed to pass regularly from organism to organism, i.e., to become infectious and thus immortal. 


\section{Conclusion}

Besides the minority of cancers arising from direct exogenous causes such as radiation, carcinogens, viruses, or inflammation, the majority of cancers do not originate from single obvious events but rather from multiple chance events in the normal life of our $3 \times 10^{13}$ cells. We link these events to the increasing entropy in the cell physiology and to the noise in our cell metabolism, which may initiate the process in some cells. This can lead to the major reverse biological transition from cells in pluricellular organisms, which obey constrains of the whole, to unicellular organisms, which independently strive to survive and multiply. After this transition to independence, the same causal mechanisms coupled to a Darwinian selection will cause the evolution to progression, invasion, metastasis, and in a few cases immortality as infectious agents. At the cellular level, this evolution will make use in a dynamic and reversible manner of the various existing normal cells programs. It will involve adaptive cell survival strategies and even apparent cooperation between cancer and normal cells from the microenvironment. This will be accompanied by a profound genomic remodeling. Finally, the cancer process, when considered from the cell point of view, is extremely inefficient at many stages: in the initiation as well as during the progression, when only rare mutations are viable and improve cell competiveness. Due the high number of cells possibly involved at the level of the organism and its lifespan, the probability of cancer and metastasis remains high.

The concept of an evolution of tumor cells to a diverse population of more and more competitive cancer cells through a process of rare consecutive stochastic genetic or epigenetic events suggests several therapeutic considerations.

First, whatever the lesions involved, the removal of a large part of the cell population in which the event takes place, i.e., the surgical approach, will greatly restrict the population in which further oncogenic events will occur. It will therefore remain fundamental.

Second, wherever the tumor has arrived in its evolution, the avoidance of further oncogenic events may delay or stop this oncogenic evolution and is therefore useful. It is well known that 5 years after abstention from smoking, the probability for lung cancer is brought back to a much lower level [249].

Third, whatever the stage of a cancer, a temporary reprieve may be helpful. In a differentiated thyroid carcinoma of a 60-year-old patient, one or two reprieves of 5 to 10 years would allow an almost normal lifespan.

Fourth, the great heterogeneity of tumor cell populations in a tumor, even with a single similar initial oncogenic event and the increase in signaling entropy which multiplies redundant signaling, suggest the interest of broad simultaneous multi-target therapies [127, 250-252].
Pending questions

- Do cancers arise from somatic stem cells, pluripotent cells, or/and from any cell?

- In the sequential multistep model of carcinogenesis (Vogelstein), may the order of oncogenic events vary?

- To what extent are micropapillary carcinomas of the thyroid, or naevi, permanently dormant cancers or newly generated tumors on the way to extinction?

- Are the cells in dormant tumors, in dormant parts of the tumor or in dormant metastases quiescent, senescent, and permanently differentiated?

- What are the roles of ncRNAs and alternative splicing?

- In real in vivo human cancers, which cells express which programs (e.g., EMT, proliferation, somatic cell characteristics, etc.)? Are these programs always or randomly expressed, exclusive of each other?

\section{Glossary}

Chromothripsis

Mitotic catastrophe caused by mitotic errors leading to widespread chromosomal rearrangements [14].

Emergence The appearance in a system of swarm intelligence, i.e., a collective behavior of a selforganized system without centralized control, composed of single entities interacting locally by a few signals (e.g., fish swarm). The tumor is composed of single tumoral and stromal cells that are our entities. They interact with signals that depend on their environment, and they undergo selective pressure. They seem to display intelligent behavior through the emergence of a sort of collective intelligence. Intelligence is not a human-restricted notion (e.g., artificial intelligence). Think of bots in video games that are, by design, intelligent entities, understanding their environment and reacting to changes in it to maximize chances of success. Remember that, before being rendered as human-looking pixels on screens, bots are lines of code on hard drives. An intelligent tumor or cell has no consciousness but adapts through selective 
pressure to its environment by reacting to its changes.

Entropy

Theoretical formulation for progressive irreversible disorder and randomness: It is a notion used in diverse fields that requires prior definition. The second principle of thermodynamics stipulates that entropy of an isolated system always increases.

In familiar terms, unless provided with new outside energy, any system constantly loses usable energy. For example, we might imagine a machine, e.g., an old car, which is machined to support a certain type of action. Whether it is left in a garage or used on a daily basis, a shift may be observable with time from its original behavior. The degradation causing this behavioral shift in machines can be linked to dissipation processes or increased macroscopic entropy and is used in modeling machine reliability. But entropy is also a statistical thermodynamics measure of disorder at a microscopic level and is, so to speak, a generalization of the macroscopic thermodynamic measurement. It is not necessarily linked to loss of usable energy but rather to the number of possible configurations of the components of the system. The cell is our system. Its internal initial order and environment determine its behavior. In the same environment, while losing this order (e.g., by acquiring mutations), the cell may behave differently. This is because of increasing entropies of gene interaction networks (entropy of signaling) that have actually been measured and compared in different publications (see main text). Consequently, increased entropy is used as a metaphor of progressive irreversible and random loss of initial order in the cell; it is strongly linked to aging

and will shape cell behavior.

Graceful degradation or fault-tolerance

Kataegis

Noise

Robustness Commons Attribution License which permits any use, distribution, and reproduction in any medium, provided the original author(s) and the source are credited.

\section{Reference}

1. Ashworth, A., Lord, C. J., \& Reis-Filho, J. S. (2011). Genetic interactions in cancer progression and treatment. Cell, 145, 30-38.

2. Teschendorff, A. E., \& Severini, S. (2010). BMC.Syst.Biol, 4, 104.

3. Kayser, K., Kayser, G., Eichhorn, S., Biechele, U., Altiner, M., Kaltner, H., et al. (1998). Association of prognosis in surgically treated lung cancer patients with cytometric, histometric and ligand histochemical properties: With an emphasis on structural entropy. Analytical and Quantitative Cytology and Histology, 20, 313-320.

4. Agrell, U. (1986). Draft of a general stochastic theory of cancer and its possible experimental verification with monoclonal multiplication of repairing and immunological systems. Medical Hypotheses, 20, 261-270.

5. West, J., Bianconi, G., Severini, S., \& Teschendorff, A. E. (2012). Differential network entropy reveals cancer system hallmarks. Sci. Rep., 2, 802.

6. Berretta, R., \& Moscato, P. (2010). Cancer biomarker discovery: The entropic hallmark. PLoS One, 5, e12262.

7. van Wieringen, W. N., \& van der Vaart, A. W. (2011). Statistical analysis of the cancer cell's molecular entropy using highthroughput data. Bioinformatics, 27.

8. Dumont, J. E., Dremier, S., Pirson, I., \& Maenhaut, C. (2002). Cross signaling, cell specificity, and physiology. American Journal of Physiology. Cell Physiology, 283, C2-28.

9. Riggs, J. E. (1994). Carcinogenesis, genetic instability and genomic entropy: Insight derived from malignant brain tumor age specific mortality rate dynamics. Journal of Theoretical Biology, 170, 331-338.

10. Stratton, M. R., Campbell, P. J., \& Futreal, P. A. (2009). The cancer genome. Nature, 458, 719-724.

11. Foulkes, W. D. (2008). Inherited susceptibility to common cancers. The New England Journal of Medicine, 359, 2143-2153. 
12. Kretzschmar, K., \& Watt, F. M. (2012). Lineage tracing. Cell, $148,33-45$.

13. Welch, J. S., Ley, T. J., Link, D. C., Miller, C. A., Larson, D. E., Koboldt, D. C., et al. (2012). The origin and evolution of mutations in acute myeloid leukemia. Cell, 150, 264-278.

14. Rausch, T., Jones, D. T., Zapatka, M., Stutz, A. M., Zichner, T., Weischenfeldt, J., et al. (2012). Genome sequencing of pediatric medulloblastoma links catastrophic DNA rearrangements with TP53 mutations. Cell, 148, 59-71.

15. Maher, C. A., \& Wilson, R. K. (2012). Chromothripsis and human disease: Piecing together the shattering process. Cell, 148, 29-32.

16. Holland, A. J., \& Cleveland, D. W. (2012). Chromoanagenesis and cancer: Mechanisms and consequences of localized, complex chromosomal rearrangements. Nature Medicine, 18, $1630-1638$.

17. Setlur, S. R., \& Lee, C. (2012). Tumor archaeology reveals that mutations love company. Cell, 149, 959-961.

18. Nik-Zainal, S., Van Loo, P., Wedge, D. C., Alexandrov, L. B., Greenman, C. D., Lau, K. W., et al. (2012). The life history of 21 breast cancers. Cell, 149, 994-1007.

19. Garcia-Cao, I., Song, M. S., Hobbs, R. M., Laurent, G., Giorgi, C., de Boer, V. C., et al. (2012). Systemic elevation of PTEN induces a tumor-suppressive metabolic state. Cell, 149, 49-62.

20. Wang, Q., \& Greene, M. I. (2008). Mechanisms of resistance to ErbB-targeted cancer therapeutics. The Journal of Clinical Investigation, 118, 2389-2392.

21. Wang, R., Chadalavada, K., Wilshire, J., Kowalik, U., Hovinga, K. E., Geber, A., et al. (2010). Glioblastoma stem-like cells give rise to tumour endothelium. Nature, 468, 829-833.

22. Sotillo, R., Schvartzman, J. M., Socci, N. D., \& Benezra, R. (2010). Mad2-induced chromosome instability leads to lung tumour relapse after oncogene withdrawal. Nature, 464, 436-440.

23. Hayden, E. J., Ferrada, E., \& Wagner, A. (2011). Cryptic genetic variation promotes rapid evolutionary adaptation in an RNA enzyme. Nature, 474, 92-95.

24. Jacobs, K. B., Yeager, M., Zhou, W., Wacholder, S., Wang, Z., Rodriguez-Santiago, B., et al. (2012). Detectable clonal mosaicism and its relationship to aging and cancer. Nature Genetics, 44, 651-658.

25. Laurie, C. C., Laurie, C. A., Rice, K., Doheny, K. F., Zelnick, L. R., McHugh, C. P., et al. (2012). Detectable clonal mosaicism from birth to old age and its relationship to cancer. Nature Genetics, 44, 642-650.

26. Jallepalli, P. V., \& Pellman, D. (2007). Cell biology. Aneuploidy in the balance. Science, 317, 904-905.

27. Sheltzer, J. M., \& Amon, A. (2011). The aneuploidy paradox: Costs and benefits of an incorrect karyotype. Trends in Genetics, $27,446-453$.

28. Pfau, S. J., \& Amon, A. (2012). Chromosomal instability and aneuploidy in cancer: From yeast to man. EMBO Reports, 13, 515-527.

29. Kolodner, R. D., Cleveland, D. W., \& Putnam, C. D. (2011). Cancer. Aneuploidy drives a mutator phenotype in cancer. Science, 333, 942-943.

30. Kim, N., \& Jinks-Robertson, S. (2012). Transcription as a source of genome instability. Nature Reviews Genetics, 13, 204-214.

31. Engellau, J., Samuelsson, V., Anderson, H., Bjerkehagen, B., Rissler, P., Sundby-Hall, K., et al. (2007). Identification of lowrisk tumours in histological high-grade soft tissue sarcomas. European Journal of Cancer, 43, 1927-1934.

32. Venet, D., Dumont, J. E., \& Detours, V. (2011). Most random gene expression signatures are significantly associated with breast cancer outcome. PLoS Computational Biology, 7, e1002240.

33. Dai, C., Dai, S., \& Cao, J. (2012). Proteotoxic stress of cancer: Implication of the heat-shock response in oncogenesis. $J$ Cell Physiol, 227, 2982-2987.
34. Deplancke, B., \& Verstrepen, K. J. (2012). Genetics. Variable outcome of mutations. Science, 335, 44-45.

35. Chen, G., Bradford, W. D., Seidel, C. W., \& Li, R. (2012). Hsp90 stress potentiates rapid cellular adaptation through induction of aneuploidy. Nature, 482, 246-250.

36. Alimonti, A., Carracedo, A., Clohessy, J. G., Trotman, L. C., Nardella, C., Egia, A., et al. (2010). Subtle variations in PTEN dose determine cancer susceptibility. Nature Genetics, 42, 454-458.

37. Frum, R. A., Khondker, Z. S., \& Kaufman, D. G. (2009). Temporal differences in DNA replication during the $\mathrm{S}$ phase using single fiber analysis of normal human fibroblasts and glioblastoma T98G cells. Cell Cycle, 8, 3133-3148.

38. Brulliard, M., Lorphelin, D., Collignon, O., Lorphelin, W., Thouvenot, B., Gothie, E., et al. (2007). Nonrandom variations in human cancer ESTs indicate that mRNA heterogeneity increases during carcinogenesis. Proceedings of the National Academy of Sciences of the United States of America, 104, 7522-7527.

39. Navin, N., Kendall, J., Troge, J., Andrews, P., Rodgers, L., McIndoo, J., et al. (2011). Tumour evolution inferred by singlecell sequencing. Nature, 472, 90-94.

40. Ogier, V., Brulliard, M., Thouvenot, B., Battais, F., Notet, V., Richard, C., et al. (2009). Decoding aberrant cancer $m R N A$ : Novel path toward diagnosis and understanding non small cell lung cancer heterogeneity. Poster presented at the 100th Annual Meeting 2009, American Association for Cancer Research, Denver, CO. Abstract retrieved from http://www.aacr.org/home/ scientists/meetings-workshops/aacr-annual-meeting-2013/previousannual-meetings/annual-meeting-2009.aspx (Program: pp 411460: Wednesday, April 22, p 33, poster 9).

41. Kimura, T., Van Keymeulen, A., Golstein, J., Fusco, A., Dumont, J. E., \& Roger, P. P. (2001). Regulation of thyroid cell proliferation by TSH and other factors: A critical evaluation of in vitro models. Endocrine Reviews, 22, 631-656.

42. Dumont, J. E., Pecasse, F., \& Maenhaut, C. (2001). Crosstalk and specificity in signalling. Are we crosstalking ourselves into general confusion? Cellular Signalling, 13, 457-463.

43. Eldar, A., \& Elowitz, M. B. (2010). Functional roles for noise in genetic circuits. Nature, 467, 167-173.

44. Pujadas, E., \& Feinberg, A. P. (2012). Regulated noise in the epigenetic landscape of development and disease. Cell, 148, 1123-1131.

45. Hansen, K. D., Timp, W., Bravo, H. C., Sabunciyan, S., Langmead, B., McDonald, O. G., et al. (2011). Increased methylation variation in epigenetic domains across cancer types. Nature Genetics, 43, 768-775.

46. Babu, M. M. (2010). Early career research award lecture. Structure, evolution and dynamics of transcriptional regulatory networks. Biochemical Society Transactions, 38, 1155-1178.

47. Pelkmans, L. (2012). Cell biology. Using cell-to-cell variability-A new era in molecular biology. Science, 336, 425-426.

48. Pickrell, J. K., Pai, A. A., Gilad, Y., \& Pritchard, J. K. (2010). Noisy splicing drives mRNA isoform diversity in human cells. PLoS Genetics, 6, e1001236.

49. Neve, P., \& Dumont, J. E. (1970). Time sequence of ultrastructural changes in the stimulated dog thyroid. Zeitschrift für Zellforschung und mikroskopische Anatomie, 103, 61-74.

50. Tay, S., Hughey, J. J., Lee, T. K., Lipniacki, T., Quake, S. R., \& Covert, M. W. (2010). Single-cell NF-kappaB dynamics reveal digital activation and analogue information processing. Nature, 466, 267-271.

51. Rovira-Graells, N., Gupta, A. P., Planet, E., Crowley, V. M., Mok, S., Ribas, d. P., et al. (2012). Transcriptional variation in the malaria parasite Plasmodium falciparum. Genome Research, 22, 925-938. 
52. Maamar, H., Raj, A., \& Dubnau, D. (2007). Noise in gene expression determines cell fate in Bacillus subtilis. Science, 317, 526-529.

53. Avery, S. V. (2006). Microbial cell individuality and the underlying sources of heterogeneity. Nature Reviews Microbiology, 4, 577-587.

54. Sigal, A., Milo, R., Cohen, A., Geva-Zatorsky, N., Klein, Y., Liron, Y., et al. (2006). Variability and memory of protein levels in human cells. Nature, 444, 643-646.

55. Snijder, B., \& Pelkmans, L. (2011). Origins of regulated cell-tocell variability. Nature Reviews Molecular Cell Biology, 12, 119125.

56. Masel, J., \& Siegal, M. L. (2009). Robustness: Mechanisms and consequences. Trends in Genetics, 25, 395-403.

57. Lestas, I., Vinnicombe, G., \& Paulsson, J. (2010). Fundamental limits on the suppression of molecular fluctuations. Nature, 467, 174-178.

58. Hahn, W. C., \& Weinberg, R. A. (2002). Modelling the molecular circuitry of cancer. Nature Reviews. Cancer, 2, 331-341.

59. Zwang, Y., Oren, M., \& Yarden, Y. (2012). Consistency test of the cell cycle: Roles for p53 and EGR1. Cancer Research, 72, 1051-1054.

60. Grbovic, O. M., Basso, A. D., Sawai, A., Ye, Q., Friedlander, P., Solit, D., et al. (2006). V600E B-Raf requires the Hsp90 chaperone for stability and is degraded in response to Hsp90 inhibitors. Proceedings of the National Academy of Sciences of the United States of America, 103, 57-62.

61. Berezikov, E. (2011). Evolution of microRNA diversity and regulation in animals. Nature Reviews Genetics, 12, 846-860.

62. Ebert, M. S., \& Sharp, P. A. (2012). Roles for microRNAs in conferring robustness to biological processes. Cell, 149, 515524.

63. Baek, D., Villen, J., Shin, C., Camargo, F. D., Gygi, S. P., \& Bartel, D. P. (2008). The impact of microRNAs on protein output. Nature, 455, 64-71.

64. Selbach, M., Schwanhausser, B., Thierfelder, N., Fang, Z., Khanin, R., \& Rajewsky, N. (2008). Widespread changes in protein synthesis induced by microRNAs. Nature, 455, 58-63.

65. Bartel, D. P. (2009). MicroRNAs: Target recognition and regulatory functions. Cell, 136, 215-233.

66. Alvarez-Saavedra, E., \& Horvitz, H. R. (2010). Many families of C. elegans microRNAs are not essential for development or viability. Current Biology, 20, 367-373.

67. Rodriguez, W., Jin, L., Janssens, V., Pierreux, C., Hick, A. C., Urizar, E., et al. (2012). Deletion of the RNaseIII enzyme dicer in thyroid follicular cells causes hypothyroidism with signs of neoplastic alterations. PLoS One, 7, e29929.

68. Bueno, M. J., de Cedron, G., Laresgoiti, U., Fernandez-Piqueras, J., Zubiaga, A. M., \& Malumbres, M. (2010). Multiple E2F-induced microRNAs prevent replicative stress in response to mitogenic signaling. Molecular and Cellular Biology, 30, 2983-2995.

69. Croce, C. M. (2009). Causes and consequences of microRNA dysregulation in cancer. Nature Reviews Genetics, 10, 704-714.

70. van Kouwenhove, M., Kedde, M., \& Agami, R. (2011). MicroRNA regulation by RNA-binding proteins and its implications for cancer. Nature Reviews. Cancer, 11, 644-656.

71. Kumar, M. S., Lu, J., Mercer, K. L., Golub, T. R., \& Jacks, T. (2007). Impaired microRNA processing enhances cellular transformation and tumorigenesis. Nature Genetics, 39, 673-677.

72. Esteller, M. (2011). Non-coding RNAs in human disease. Nature Reviews Genetics, 12, 861-874.

73. Voorhoeve, P. M. (2010). MicroRNAs: Oncogenes, tumor suppressors or master regulators of cancer heterogeneity? Biochimica et Biophysica Acta, 1805, 72-86.

74. Lopez-Serra, P., \& Esteller, M. (2012). DNA methylationassociated silencing of tumor-suppressor microRNAs in cancer. Oncogene, 31, 1609-1622.
75. Trang, P., Weidhaas, J. B., \& Slack, F. J. (2008). MicroRNAs as potential cancer therapeutics. Oncogene, 27(2), S52-S57.

76. Maillot, G., Lacroix-Triki, M., Pierredon, S., Gratadou, L., Schmidt, S., Benes, V., et al. (2009). Widespread estrogendependent repression of microRNAs involved in breast tumor cell growth. Cancer Research, 69, 8332-8340.

77. Lujambio, A., \& Lowe, S. W. (2012). The microcosmos of cancer. Nature, 482, 347-355.

78. Ravi, A., Gurtan, A. M., Kumar, M. S., Bhutkar, A., Chin, C., Lu, V., et al. (2012). Proliferation and tumorigenesis of a murine sarcoma cell line in the absence of DICER1. Cancer Cell, 21, $848-855$.

79. Vinuela, A., Snoek, L. B., Riksen, J. A., \& Kammenga, J. E. (2010). Genome-wide gene expression regulation as a function of genotype and age in C. elegans. Genome Research, 20, 929-937.

80. Diderich, K., Alanazi, M., \& Hoeijmakers, J. H. (2011). Premature aging and cancer in nucleotide excision repairdisorders. DNA Repair (Amst), 10, 772-780.

81. de Magalhaes, J. P., Curado, J., \& Church, G. M. (2009). Metaanalysis of age-related gene expression profiles identifies common signatures of aging. Bioinformatics, 25, 875-881.

82. Lushnikova, T., Bouska, A., Odvody, J., Dupont, W. D., \& Eischen, C. M. (2011). Aging mice have increased chromosome instability that is exacerbated by elevated $\mathrm{Mdm} 2$ expression. Oncogene, 30, 4622-4631.

83. Michod, R. E. (2007). Evolution of individuality during the transition from unicellular to multicellular life. Proceedings of the National Academy of Sciences of the United States of America, 104(1), 8613-8618.

84. Hanahan, D., \& Weinberg, R. A. (2011). Hallmarks of cancer: The next generation. Cell, 144, 646-674.

85. Srivastava, M., Simakov, O., Chapman, J., Fahey, B., Gauthier, M. E., Mitros, T., et al. (2010). The Amphimedon queenslandica genome and the evolution of animal complexity. Nature, 466, 720 726.

86. Lugini, L., Matarrese, P., Tinari, A., Lozupone, F., Federici, C., Iessi, E., et al. (2006). Cannibalism of live lymphocytes by human metastatic but not primary melanoma cells. Cancer Research, 66, 3629-3638.

87. Overholtzer, M., Mailleux, A. A., Mouneimne, G., Normand, G., Schnitt, S. J., King, R. W., et al. (2007). A nonapoptotic cell death process, entosis, that occurs by cell-in-cell invasion. Cell, 131, 966-979.

88. Hanahan, D., \& Weinberg, R. A. (2000). The hallmarks of cancer. Cell, 100, 57-70.

89. Kuppers, M., Faust, D., Linz, B., \& Dietrich, C. (2011). Regulation of ERK1/2 activity upon contact inhibition in fibroblasts. Biochemical and Biophysical Research Communications, 406, 483-487.

90. Baylin, S. B., \& Jones, P. A. (2011). A decade of exploring the cancer epigenome-Biological and translational implications. Nature Reviews. Cancer, 11, 726-734.

91. Rubin, H. (2011). Fields and field cancerization: The preneoplastic origins of cancer: asymptomatic hyperplastic fields are precursors of neoplasia, and their progression to tumors can be tracked by saturation density in culture. BioEssays, 33, 224231.

92. Kamarajugadda, S., Stemboroski, L., Cai, Q., Simpson, N. E., Nayak, S., Tan, M., et al. (2012). Glucose oxidation modulates anoikis and tumor metastasis. Molecular and Cellular Biology, 32, 1893-1907.

93. Bissell, M. J., \& Hines, W. C. (2011). Why don't we get more cancer? A proposed role of the microenvironment in restraining cancer progression. Nature Medicine, 17, 320-329.

94. Rubin, H. (2008). Cell-cell contact interactions conditionally determine suppression and selection of the neoplastic phenotype. 
Proceedings of the National Academy of Sciences of the United States of America, 105, 6215-6221.

95. Gordon, D. J., Resio, B., \& Pellman, D. (2012). Causes and consequences of aneuploidy in cancer. Nature Reviews Genetics, 13, 189-203.

96. Leung, C. T., \& Brugge, J. S. (2012). Outgrowth of single oncogene-expressing cells from suppressive epithelial environments. Nature, 482, 410-413.

97. Mesnil, M., Crespin, S., Avanzo, J. L., \& Zaidan-Dagli, M. L. (2005). Defective gap junctional intercellular communication in the carcinogenic process. Biochimica et Biophysica Acta, 1719, $125-145$.

98. Matter, K., \& Balda, M. S. (2007). Epithelial tight junctions, gene expression and nucleo-junctional interplay. Journal of Cell Science, 120, 1505-1511.

99. Saadat, I., Higashi, H., Obuse, C., Umeda, M., Murata-Kamiya, N., Saito, Y., et al. (2007). Helicobacter pylori CagA targets PAR1/ MARK kinase to disrupt epithelial cell polarity. Nature, 447, 330333.

100. Radisky, D. C., \& Bissell, M. J. (2006). Matrix metalloproteinaseinduced genomic instability. Current Opinion in Genetics and Development, 16, 45-50.

101. McCaffrey, L. M., \& Macara, I. G. (2011). Epithelial organization, cell polarity and tumorigenesis. Trends in Cell Biology, 21, 727-735.

102. Driessens, G., Beck, B., Caauwe, A., Simons, B. D., \& Blanpain, C. (2012). Defining the mode of tumour growth by clonal analysis. Nature, 488, 527-530.

103. Tomas, G., Tarabichi, M., Gacquer, D., Hebrant, A., Dom, G., Dumont, J. E., et al. (2012). A general method to derive robust organ-specific gene expression-based differentiation indices: application to thyroid cancer diagnostic. Oncogene, 31, 4490-4498.

104. Harding, C., Pompei, F., \& Wilson, R. (2012). Peak and decline in cancer incidence, mortality, and prevalence at old ages. Cancer, $118,1371-1386$

105. de Beco, S., Ziosi, M., \& Johnston, L. A. (2012). New frontiers in cell competition. Developmental Dynamics, 241, 831-841.

106. Johnston, L. A. (2009). Competitive interactions between cells: Death, growth, and geography. Science, 324, 1679-1682.

107. Marinari, E., Mehonic, A., Curran, S., Gale, J., Duke, T., \& Baum, B. (2012). Live-cell delamination counterbalances epithelial growth to limit tissue overcrowding. Nature, 484, 542-545.

108. Eisenhoffer, G. T., Loftus, P. D., Yoshigi, M., Otsuna, H., Chien, C. B., Morcos, P. A., et al. (2012). Crowding induces live cell extrusion to maintain homeostatic cell numbers in epithelia. Nature, 484, 546-549.

109. Portela, M., Casas-Tinto, S., Rhiner, C., Lopez-Gay, J. M., Dominguez, O., Soldini, D., et al. (2010). Drosophila SPARC is a self-protective signal expressed by loser cells during cell competition. Developmental Cell, 19, 562-573.

110. Franklin, W. A., Gazdar, A. F., Haney, J., Wistuba, I. I., La Rosa, F. G., Kennedy, T., et al. (1997). Widely dispersed p53 mutation in respiratory epithelium. A novel mechanism for field carcinogenesis. The Journal of Clinical Investigation, 100, 2133-2137.

111. Pearson, H. B., Perez-Mancera, P. A., Dow, L. E., Ryan, A., Tennstedt, P., Bogani, D., et al. (2011). SCRIB expression is deregulated in human prostate cancer, and its deficiency in mice promotes prostate neoplasia. The Journal of Clinical Investigation, 121, 4257-4267.

112. Zhao, B., Tumaneng, K., \& Guan, K. L. (2011). The Hippo pathway in organ size control, tissue regeneration and stem cell self-renewal. Nature Cell Biology, 13, 877-883.

113. Chen, X., Sun, H., Ren, S., Kim, C. V., Zhang, L., Zhou, S., et al. (2012). Association of XRCC3 and XPD751 SNP with efficacy of platinum-based chemotherapy in advanced NSCLC patients. Clinical and Translational Oncology, 14, 207-213.
114. Chen, C. L., Schroeder, M. C., Kango-Singh, M., Tao, C., \& Halder, G. (2012). Tumor suppression by cell competition through regulation of the Hippo pathway. Proceedings of the National Academy of Sciences of the United States of America, 109, 484-489.

115. Tumaneng, K., Russell, R. C., \& Guan, K. L. (2012). Organ size control by Hippo and TOR pathways. Current Biology, 22, R368-R379.

116. Farber, E. (1996). The step-by-step development of epithelial cancer: From phenotype to genotype. Advances in Cancer Research, 70, 21-48.

117. Greaves, M., \& Maley, C. C. (2012). Clonal evolution in cancer. Nature, 481, 306-313.

118. Nik-Zainal, S., Alexandrov, L. B., Wedge, D. C., Van Loo, P., Greenman, C. D., Raine, K., et al. (2012). Mutational processes molding the genomes of 21 breast cancers. Cell, 149, 979-993.

119. Ma, Q. C., Ennis, C. A., \& Aparicio, S. (2012). Opening Pandora's Box-The new biology of driver mutations and clonal evolution in cancer as revealed by next generation sequencing. Current Opinion in Genetics and Development, 22, 3-9.

120. Sprouffske, K., Merlo, L. M., Gerrish, P. J., Maley, C. C., \& Sniegowski, P. D. (2012). Cancer in light of experimental evolution. Current Biology, 22, R762-R771.

121. Loeb, L. A. (2011). Human cancers express mutator phenotypes: Origin, consequences and targeting. Nature Reviews. Cancer, 11, $450-457$.

122. Bartkova, J., Horejsi, Z., Koed, K., Kramer, A., Tort, F., Zieger, K., et al. (2005). DNA damage response as a candidate anticancer barrier in early human tumorigenesis. Nature, 434, 864 870.

123. Close, P., East, P., Dirac-Svejstrup, A. B., Hartmann, H., Heron, M., Maslen, S., et al. (2012). DBIRD complex integrates alternative mRNA splicing with RNA polymerase II transcript elongation. Nature, 484, 386-389.

124. Solimini, N. L., Luo, J., \& Elledge, S. J. (2007). Non-oncogene addiction and the stress phenotype of cancer cells. Cell, 130, 986988.

125. Yates, L. R., \& Campbell, P. J. (2012). Evolution of the cancer genome. Nature Reviews Genetics, 13, 795-806.

126. Ding, L., Ley, T. J., Larson, D. E., Miller, C. A., Koboldt, D. C., Welch, J. S., et al. (2012). Clonal evolution in relapsed acute myeloid leukaemia revealed by whole-genome sequencing. Nature, 481, 506-510.

127. Bhatia, S., Frangioni, J. V., Hoffman, R. M., Iafrate, A. J., \& Polyak, K. (2012). The challenges posed by cancer heterogeneity. Nature Biotechnology, 30, 604-610.

128. Vincent, A., \& Van, S. I. (2012). On the epigenetic origin of cancer stem cells. Biochimica et Biophysica Acta, 1826, 83-88.

129. Akhtar-Zaidi, B., Cowper-Sal-lari, R., Corradin, O., Saiakhova, A., Bartels, C. F., Balasubramanian, D., et al. (2012). Epigenomic enhancer profiling defines a signature of colon cancer. Science, 336, 736-739.

130. Helman, E., Naxerova, K., \& Kohane, I. S. (2012). DNA hypermethylation in lung cancer is targeted at differentiationassociated genes. Oncogene, 31, 1181-1188.

131. Holmberg, J., \& Perlmann, T. (2012). Maintaining differentiated cellular identity. Nature Reviews Genetics, 13, 429-439.

132. Maenhaut, C., Dumont, J. E., Roger, P. P., \& van Staveren, W. C. (2010). Cancer stem cells: A reality, a myth, a fuzzy concept or a misnomer? An analysis. Carcinogenesis, 31, 149-158.

133. Swanton, C. (2012). Intratumor heterogeneity: Evolution through space and time. Cancer Research, 72, 4875-4882.

134. Gerlinger, M., Rowan, A. J., Horswell, S., Larkin, J., Endesfelder, D., Gronroos, E., et al. (2012). Intratumor heterogeneity and branched evolution revealed by multiregion sequencing. The New England Journal of Medicine, 366, 883-892. 
135. Xu, X., Hou, Y., Yin, X., Bao, L., Tang, A., Song, L., et al. (2012). Single-cell exome sequencing reveals singlenucleotide mutation characteristics of a kidney tumor. Cell, $148,886-895$.

136. Li, Y., \& Sea, X. X. L. (2012). Single-cell sequencing analysis characterizes common and cell-lineage-specific mutations in a muscle-invasive bladder cancer. Giga Science, 1, 12.

137. Yea, L. (2012). Single-cell sequencing analysis characterizes common and cell-lineage-specific mutations in a muscleinvasive bladder cancer. GigaScience, 1, 12.

138. Kohtz, C. (2011). Engaging students in an undergraduate research course. Nurse Educator, 36, 150-154.

139. Kaiser, J. (2011). Combining targeted drugs to stop resistant tumors. Science, 331, 1542-1545.

140. Frum, R. A., Khondker, Z. S., \& Kaufman, D. G. (2009). Temporal differences in DNA replication during the $\mathrm{S}$ phase using single fiber analysis of normal human fibroblasts and glioblastoma T98G cells. Cell Cycle, 8, 3133-3148.

141. Bardelli, A., \& Janne, P. A. (2012). The road to resistance: EGFR mutation and cetuximab. Nature Medicine, 18, 199-200.

142. Su, F., Viros, A., Milagre, C., Trunzer, K., Bollag, G., Spleiss, O., et al. (2012). RAS mutations in cutaneous squamous-cell carcinomas in patients treated with BRAF inhibitors. The New England Journal of Medicine, 366, 207-215.

143. Aziz, M. H., Shen, H., \& Maki, C. G. (2011). Acquisition of p53 mutations in response to the non-genotoxic p53 activator Nutlin3. Oncogene, 30, 4678-4686.

144. Shay, J. W., Reddel, R. R., \& Wright, W. E. (2012). Cancer. Cancer and telomeres-An ALTernative to telomerase. Science, 336, 1388-1390.

145. Lambert, G., Estevez-Salmeron, L., Oh, S., Liao, D., Emerson, B. M., Tlsty, T. D., et al. (2011). An analogy between the evolution of drug resistance in bacterial communities and malignant tissues. Nature Reviews. Cancer, 11, 375-382.

146. Muller, F. L., Colla, S., Aquilanti, E., Manzo, V. E., Genovese, G., Lee, J., et al. (2012). Passenger deletions generate therapeutic vulnerabilities in cancer. Nature, 488, 337-342.

147. Nijhawan, D., Zack, T. I., Ren, Y., Strickland, M. R., Lamothe, R., Schumacher, S. E., et al. (2012). Cancer vulnerabilities unveiled by genomic loss. Cell, 150, 842-854.

148. Khan, A. I., Dinh, D. M., Schneider, D., Lenski, R. E., \& Cooper, T. F. (2011). Negative epistasis between beneficial mutations in an evolving bacterial population. Science, 332, 1193-1196.

149. Malaise, E. P., Chavaudra, N., \& Tubiana, M. (1973). The relationship between growth rate, labelling index and histological type of human solid tumours. European Journal of Cancer, 9, 305-312.

150. Magee, J. A., Piskounova, E., \& Morrison, S. J. (2012). Cancer stem cells: Impact, heterogeneity, and uncertainty. Cancer Cell, 21, 283-296.

151. Gupta, P. B., Fillmore, C. M., Jiang, G., Shapira, S. D., Tao, K., Kuperwasser, C., et al. (2011). Stochastic state transitions give rise to phenotypic equilibrium in populations of cancer cells. Cell, $146,633-644$

152. Friedl, P., \& Wolf, K. (2003). Tumour-cell invasion and migration: Diversity and escape mechanisms. Nature Reviews. Cancer, 3, 362-374.

153. Ferreira LM, Hebrant A, Dumont JE (2012): Metabolic reprogramming of the tumor. Oncogene.

154. Jones, R. G., \& Thompson, C. B. (2009). Tumor suppressors and cell metabolism: A recipe for cancer growth. Genes \& Development, 23, 537-548.

155. Berardi, M. J., \& Fantin, V. R. (2011). Survival of the fittest: Metabolic adaptations in cancer. Current Opinion in Genetics and Development, 21, 59-66.

156. Noh KH, Lee YH, Jeon JH, Kang TH, Mao CP, Wu TC, Kim TW (2012): Cancer vaccination drives Nanog-dependent evolution of tumor cells towards an immune-resistant and stem-like phenotype. Cancer Res 72:1717-1727

157. Barsoum, I. B., Hamilton, T. K., Li, X., Cotechini, T., Miles, E. A., Siemens, D. R., et al. (2011). Hypoxia induces escape from innate immunity in cancer cells via increased expression of ADAM10: Role of nitric oxide. Cancer Research, 71, 74337441.

158. Facciabene, A., Peng, X., Hagemann, I. S., Balint, K., Barchetti, A., Wang, L. P., et al. (2011). Tumour hypoxia promotes tolerance and angiogenesis via CCL28 and T(reg) cells. Nature, 475, 226-230.

159. Hirschhaeuser, F., Sattler, U. G., \& Mueller-Klieser, W. (2011). Lactate: A metabolic key player in cancer. Cancer Research, 71, 6921-6925.

160. De Bock, K., Cauwenberghs, S., \& Carmeliet, P. (2011). Vessel abnormalization: Another hallmark of cancer? Molecular mechanisms and therapeutic implications. Current Opinion in Genetics and Development, 21, 73-79.

161. Bertos, N. R., \& Park, M. (2011). Breast cancer-One term, many entities? The Journal of Clinical Investigation, 121, 3789-3796.

162. Polyak, K. (2011). Heterogeneity in breast cancer. The Journal of Clinical Investigation, 121, 3786-3788.

163. Dornan, D., \& Settleman, J. (2011). Dissecting cancer heterogeneity. Nature Biotechnology, 29, 1095-1096.

164. Lotem, J., Netanely, D., Domany, E., \& Sachs, L. (2005). Human cancers overexpress genes that are specific to a variety of normal human tissues. Proceedings of the National Academy of Sciences of the United States of America, 102, 18556-18561.

165. Dvorak, H. F. (1986). Tumors: Wounds that do not heal. Similarities between tumor stroma generation and wound healing. The New England Journal of Medicine, 315, 16501659.

166. Jacobs, P. P., \& Sackstein, R. (2011). CD44 and HCELL: Preventing hematogenous metastasis at step 1. FEBS Letters, 585, 3148-3158.

167. Colombo, S. L., Palacios-Callender, M., Frakich, N., De Leon, J., Schmitt, C. A., Boorn, L., et al. (2010). Anaphase-promoting complex/cyclosome-Cdh1 coordinates glycolysis and glutaminolysis with transition to $\mathrm{S}$ phase in human $\mathrm{T}$ lymphocytes. Proceedings of the National Academy of Sciences of the United States of America, 107, 18868-18873.

168. Almeida, A., Bolanos, J. P., \& Moncada, S. (2010). E3 ubiquitin ligase APC/C-Cdh1 accounts for the Warburg effect by linking glycolysis to cell proliferation. Proceedings of the National Academy of Sciences of the United States of America, 107, 738-741.

169. Liu, H., Radisky, D. C., Yang, D., Xu, R., Radisky, E. S., Bissell, M. J., et al. (2012). MYC suppresses cancer metastasis by direct transcriptional silencing of alpha(v) and beta(3) integrin subunits. Nature Cell Biology, 14, 567-574.

170. Nikolsky, Y., Sviridov, E., Yao, J., Dosymbekov, D., Ustyansky, V., Kaznacheev, V., et al. (2008). Genome-wide functional synergy between amplified and mutated genes in human breast cancer. Cancer Research, 68, 9532-9540.

171. Liu, P., Cheng, H., Santiago, S., Raeder, M., Zhang, F., Isabella, A., et al. (2011). Oncogenic PIK3CA-driven mammary tumors frequently recur via PI3K pathway-dependent and PI3K pathwayindependent mechanisms. Nature Medicine, 17, 1116-1120.

172. Wilson, T. R., Fridlyand, J., Yan, Y., Penuel, E., Burton, L., Chan, E., et al. (2012). Widespread potential for growth-factor-driven resistance to anticancer kinase inhibitors. Nature, 487, 505-509.

173. Koppikar, P., Bhagwat, N., Kilpivaara, O., Manshouri, T., Adli, M., Hricik, T., et al. (2012). Heterodimeric JAK-STAT activation as a mechanism of persistence to JAK2 inhibitor therapy. Nature, $489,155-159$. 
174. Misale, S., Yaeger, R., Hobor, S., Scala, E., Janakiraman, M., Liska, D., et al. (2012). Emergence of KRAS mutations and acquired resistance to anti-EGFR therapy in colorectal cancer. Nature, 486, 532-536.

175. Creixell, P., Schoof, E. M., Erler, J. T., \& Linding, R. (2012). Navigating cancer network attractors for tumor-specific therapy. Nature Biotechnology, 30, 842-848.

176. Celia-Terrassa, T., Meca-Cortes, O., Mateo, F., de Paz, A. M., Rubio, N., Arnal-Estape, A., et al. (2012). Epithelialmesenchymal transition can suppress major attributes of human epithelial tumor-initiating cells. The Journal of Clinical Investigation, 122, 1849-1868.

177. Friedl, P., \& Alexander, S. (2011). Cancer invasion and the microenvironment: Plasticity and reciprocity. Cell, 147, 992-1009.

178. The Cancer Genome Atlas Network. Gehlenborg NKRea. (2012). Comprehensive molecular characterization of human colon and rectal cancer. Nature, 487, 330-337.

179. Koboldt DC, McLellan MD, Schimdt H, Cancer Genome Atlas Network (2012): Comprehensive molecular portraits of human breast tumours. Nature 490:61-70.

180. Christophe-Hobertus, C., Lefort, A., Libert, F., \& Christophe, D. (2012). Functional inactivation of thyroid transcription factor-1 in PCCl3 thyroid cells. Molecular and Cellular Endocrinology, 358, $36-45$.

181. Floor, S., van Staveren, W. C., Larsimont, D., Dumont, J. E., \& Maenhaut, C. (2011). Cancer cells in epithelial-tomesenchymal transition and tumor-propagating-cancer stem cells: Distinct, overlapping or same populations. Oncogene, 30, 4609-4621.

182. Lawlor, E. R., Soucek, L., Brown-Swigart, L., Shchors, K., Bialucha, C. U., \& Evan, G. I. (2006). Reversible kinetic analysis of Myc targets in vivo provides novel insights into Myc-mediated tumorigenesis. Cancer Research, 66, 4591-4601.

183. Prahallad, A., Sun, C., Huang, S., Di Nicolantonio, F., Salazar, R., Zecchin, D., et al. (2012). Unresponsiveness of colon cancer to BRAF(V600E) inhibition through feedback activation of EGFR. Nature, 483, 100-103.

184. Sawyers, C. L. (2007). Cancer: mixing cocktails. Nature, 449, 993-996.

185. Kim, H. Y., Park, W. Y., Lee, K. E., Park, W. S., Chung, Y. S., Cho, S. J., et al. (2010). Comparative analysis of gene expression profiles of papillary thyroid microcarcinoma and papillary thyroid carcinoma. Journal of Cancer Research and Therapeutics, 6 , 452-457.

186. Pazaitou-Panayiotou, K., Capezzone, M., \& Pacini, F. (2007). Clinical features and therapeutic implication of papillary thyroid microcarcinoma. Thyroid, 17, 1085-1092.

187. Peeper, D. S. (2011). Oncogene-induced senescence and melanoma: Where do we stand? Pigment Cell \& Melanoma Research, 24, 1107-1111.

188. Rice, J. (2012). Metastasis: The rude awakening. Nature, 485, S55-S57.

189. Saab, R. (2011). Senescence and pre-malignancy: How do tumors progress? Seminars in Cancer Biology, 21, 385-391.

190. Melief, C. J. (2007). Cancer: Immune pact with the enemy. Nature, 450, 803-804.

191. Ramaswamy, S., Ross, K. N., Lander, E. S., \& Golub, T. R. (2003). A molecular signature of metastasis in primary solid tumors. Nature Genetics, 33, 49-54.

192. Wu, M., Pastor-Pareja, J. C., \& Xu, T. (2010). Interaction between Ras(V12) and scribbled clones induces tumour growth and invasion. Nature, 463, 545-548.

193. Campbell, P. J., Yachida, S., Mudie, L. J., Stephens, P. J., Pleasance, E. D., Stebbings, L. A., et al. (2010). The patterns and dynamics of genomic instability in metastatic pancreatic cancer. Nature, 467, 1109-1113.
194. Natoli, C., Ramazzotti, V., Nappi, O., Giacomini, P., Palmeri, S., Salvatore, M., et al. (2011). Unknown primary tumors. Biochimica et Biophysica Acta, 1816, 13-24.

195. Valastyan, S., \& Weinberg, R. A. (2011). Tumor metastasis: Molecular insights and evolving paradigms. Cell, 147, 275-292.

196. Brooks, S. A., Lomax-Browne, H. J., Carter, T. M., Kinch, C. E., \& Hall, D. M. (2010). Molecular interactions in cancer cell metastasis. Acta Histochemica, 112, 3-25.

197. Alonso, S. R., Tracey, L., Ortiz, P., Perez-Gomez, B., Palacios, J., Pollan, M., et al. (2007). A high-throughput study in melanoma identifies epithelial-mesenchymal transition as a major determinant of metastasis. Cancer Research, 67, 3450-3460.

198. Carmeliet, P., \& Jain, R. K. (2011). Principles and mechanisms of vessel normalization for cancer and other angiogenic diseases. Nature Reviews. Drug Discovery, 10, 417-427.

199. Mierke, C. T. (2012). Endothelial cell's biomechanical properties are regulated by invasive cancer cells. Molecular BioSystems, 8 , 1639-1649.

200. Podsypanina, K., Du, Y. C., Jechlinger, M., Beverly, L. J., Hambardzumyan, D., \& Varmus, H. (2008). Seeding and propagation of untransformed mouse mammary cells in the lung. Science, 321, 1841-1844.

201. Luzzi, K. J., MacDonald, I. C., Schmidt, E. E., Kerkvliet, N., Morris, V. L., Chambers, A. F., et al. (1998). Multistep nature of metastatic inefficiency: Dormancy of solitary cells after successful extravasation and limited survival of early micrometastases. The American Journal of Pathology, 153, 865-873.

202. Oskarsson, T., Acharyya, S., Zhang, X. H., Vanharanta, S., Tavazoie, S. F., Morris, P. G., et al. (2011). Breast cancer cells produce tenascin $\mathrm{C}$ as a metastatic niche component to colonize the lungs. Nature Medicine, 17, 867-874.

203. Tabaries, S., Dupuy, F., Dong, Z., Monast, A., Annis, M. G., Spicer, J., et al. (2012). Claudin-2 promotes breast cancer liver metastasis by facilitating tumor cell interactions with hepatocytes. Molecular and Cellular Biology, 32, 2979-2991.

204. Duda, D. G., Duyverman, A. M., Kohno, M., Snuderl, M., Steller, E. J., Fukumura, D., et al. (2010). Malignant cells facilitate lung metastasis by bringing their own soil. Proceedings of the National Academy of Sciences of the United States of America, 107, 21677-21682.

205. Friedl, P., Locker, J., Sahai, E., \& Segall, J. E. (2012). Classifying collective cancer cell invasion. Nature Cell Biology, 14, 777-783.

206. Rebbeck, C. A., Leroi, A. M., \& Burt, A. (2011). Mitochondrial capture by a transmissible cancer. Science, 331, 303.

207. Murchison, E. P. (2008). Clonally transmissible cancers in dogs and Tasmanian devils. Oncogene, 27(2), S19-S30.

208. Murgia, C., Pritchard, J. K., Kim, S. Y., Fassati, A., \& Weiss, R. A. (2006). Clonal origin and evolution of a transmissible cancer. Cell, 126, 477-487.

209. Belov, K. (2012). Contagious cancer: Lessons from the devil and the dog. BioEssays, 34, 285-292.

210. Isoda, T., Ford, A. M., Tomizawa, D., van Delft, F. W., De Castro, D. G., Mitsuiki, N., et al. (2009). Immunologically silent cancer clone transmission from mother to offspring. Proceedings of the National Academy of Sciences of the United States of America, 106, 17882-17885.

211. Sala-Torra, O., Hanna, C., Loken, M. R., Flowers, M. E., Maris, M., Ladne, P. A., et al. (2006). Evidence of donor-derived hematologic malignancies after hematopoietic stem cell transplantation. Biology of Blood and Marrow Transplantation, 12, 511-517.

212. Myron, K. H., McBride, M. A., Cherikh, W. S., Spain, P. C., Marks, W. H., \& Roza, A. M. (2002). Transplant tumor registry: Donor related malignancies. Transplantation, 74, 358-362.

213. Bersini, H. (2010). Emergent phenomena belong only to biology. Synthese Springer Science-Business:Synthese . doi:10.1007/ s11229-010-9724-4. 
214. Rorth, P. (2012). Fellow travellers: Emergent properties of collective cell migration. EMBO Reports, 13, 984-991.

215. Monod H, Lemaire C, Delavelle F, Saint-Saens M (1972): [Static work capacity in hypoxia]. J.Physiol (Paris) 65:Suppl 3:455A.

216. Brown, S. P., \& Johnstone, R. A. (2001). Cooperation in the dark: Signalling and collective action in quorum-sensing bacteria. Proc. Biol. Sci., 268, 961-965.

217. Davidson, E. H. (2010). Emerging properties of animal gene regulatory networks. Nature, 468, 911-920.

218. Van der Veldt, A. A., Lubberink, M., Bahce, I., Walraven, M., de Boer, M. P., Greuter, H. N., et al. (2012). Rapid decrease in delivery of chemotherapy to tumors after anti-VEGF therapy: Implications for scheduling of anti-angiogenic drugs. Cancer Cell, 21, 82-91.

219. Chang, Q., Jurisica, I., Do, T., \& Hedley, D. W. (2011). Hypoxia predicts aggressive growth and spontaneous metastasis formation from orthotopically grown primary xenografts of human pancreatic cancer. Cancer Research, 71, 3110-3120.

220. Lee, S. L., Rouhi, P., Dahl, J. L., Zhang, D., Ji, H., Hauptmann, G., et al. (2009). Hypoxia-induced pathological angiogenesis mediates tumor cell dissemination, invasion, and metastasis in a zebrafish tumor model. Proceedings of the National Academy of Sciences of the United States of America, 106, 19485-19490.

221. Hashimoto, O., Shimizu, K., Semba, S., Chiba, S., Ku, Y., Yokozaki, H., et al. (2011). Hypoxia induces tumor aggressiveness and the expansion of CD133-positive cells in a hypoxiainducible factor-1alpha-dependent manner in pancreatic cancer cells. Pathobiology, 78, 181-192.

222. Liu, S., Kumar, S. M., Martin, J. S., Yang, R., \& Xu, X. (2011). Snaill mediates hypoxia-induced melanoma progression. The American Journal of Pathology, 179, 3020-3031.

223. Keith, B., \& Simon, M. C. (2007). Hypoxia-inducible factors, stem cells, and cancer. Cell, 129, 465-472.

224. Michieli, P. (2009). Hypoxia, angiogenesis and cancer therapy: To breathe or not to breathe? Cell Cycle, 8, 3291-3296.

225. Walenta, S., Wetterling, M., Lehrke, M., Schwickert, G., Sundfor, K., Rofstad, E. K., et al. (2000). High lactate levels predict likelihood of metastases, tumor recurrence, and restricted patient survival in human cervical cancers. Cancer Research, 60, 916-921.

226. Ricci-Vitiani, L., Pallini, R., Biffoni, M., Todaro, M., Invernici, G., Cenci, T., et al. (2010). Tumour vascularization via endothelial differentiation of glioblastoma stem-like cells. Nature, 468, 824-828.

227. Semenza, G. L. (2010). Defining the role of hypoxia-inducible factor 1 in cancer biology and therapeutics. Oncogene, 29, 625-634.

228. Alexander, S., \& Friedl, P. (2012). Cancer invasion and resistance: Interconnected processes of disease progression and therapy failure. Trends in Molecular Medicine, 18, 13-26.

229. Soon, P. S., Kim, E., Pon, C. K., Gill, A. J., Moore, K., Spillane, A. J., et al. (2013). Breast cancer-associated fibroblasts induce epithelial-to-mesenchymal transition in breast cancer cells. Endocr Relat Cancer, 20, 1-12.

230. Goetz, J. G., Minguet, S., Navarro-Lerida, I., Lazcano, J. J., Samaniego, R., Calvo, E., et al. (2011). Biomechanical remodeling of the microenvironment by stromal caveolin-1 favors tumor invasion and metastasis. Cell, 146, 148-163.

231. Xue, Y., Lim, S., Yang, Y., Wang, Z., Jensen, L. D., Hedlund, E. M., et al. (2012). PDGF-BB modulates hematopoiesis and tumor angiogenesis by inducing erythropoietin production in stromal cells. Nature Medicine, 18, 100-110.

232. Roodhart, J. M., Daenen, L. G., Stigter, E. C., Prins, H. J., Gerrits, J., Houthuijzen, J. M., et al. (2011). Mesenchymal stem cells induce resistance to chemotherapy through the release of platinum-induced fatty acids. Cancer Cell, 20, 370-383.
233. Zhang, M., Yang, J., Tao, L., Li, L., Ma, P., \& Fawcett, J. P. (2012). Acarbose bioequivalence: Exploration of new pharmacodynamic parameters. The AAPS Journal, 14, 345-351.

234. Kosaka, N., Iguchi, H., Yoshioka, Y., Hagiwara, K., Takeshita, F., \& Ochiya, T. (2012). Competitive interactions of cancer cells and normal cells via secretory microRNAs. The Journal of Biological Chemistry, 287, 1397-1405.

235. Rodier, F., \& Campisi, J. (2011). Four faces of cellular senescence. The Journal of Cell Biology, 192, 547-556.

236. Mione, M., \& Zon, L. I. (2012). Cancer and inflammation: An aspirin a day keeps the cancer at bay. Current Biology, 22, R522R525.

237. DuPage, M., Mazumdar, C., Schmidt, L. M., Cheung, A. F., \& Jacks, T. (2012). Expression of tumour-specific antigens underlies cancer immunoediting. Nature, 482, 405-409.

238. Schreiber, R. D., Old, L. J., \& Smyth, M. J. (2011). Cancer immunoediting: Integrating immunity's roles in cancer suppression and promotion. Science, 331, 1565-1570.

239. Calcinotto, A., Filipazzi, P., Grioni, M., Iero, M., De Milito, A., Ricupito, A., et al. (2012). Modulation of microenvironment acidity reverses anergy in human and murine tumor-infiltrating T lymphocytes. Cancer Research, 72, 2746-2756.

240. Han, C. Z., \& Ravichandran, K. S. (2011). Metabolic connections during apoptotic cell engulfment. Cell, 147, 1442-1445.

241. Kawada, K., \& Taketo, M. M. (2011). Significance and mechanism of lymph node metastasis in cancer progression. Cancer Research, 71, 1214-1218.

242. Huang, Q., Li, F., Liu, X., Li, W., Shi, W., Liu, F. F., et al. (2011). Caspase 3-mediated stimulation of tumor cell repopulation during cancer radiotherapy. Nature Medicine, 17, 860-866.

243. Sonveaux, P., Brouet, A., Havaux, X., Gregoire, V., Dessy, C., Balligand, J. L., et al. (2003). Irradiation-induced angiogenesis through the up-regulation of the nitric oxide pathway: Implications for tumor radiotherapy. Cancer Research, 63, 1012-1019.

244. Kaplan, L. M., Fallon, J. A., Mun, E. C., Harvey, A. M., Kastrinakis, W. V., Johnson, E. Q., et al. (2005). Coding and reimbursement for weight loss surgery: Best practice recommendations. Obesity Research, 13, 290-300.

245. Werbowetski-Ogilvie, T. E., Schnerch, A., Rampalli, S., Mills, C. E., Lee, J. B., Hong, S. H., et al. (2011). Evidence for the transmission of neoplastic properties from transformed to normal human stem cells. Oncogene, 30, 4632-4644.

246. Sawyers, C. L. (2009). Shifting paradigms: The seeds of oncogene addiction. Nature Medicine, 15, 1158-1161.

247. Shackleton, M., Vaillant, F., Simpson, K. J., Stingl, J., Smyth, G. K., Asselin-Labat, M. L., et al. (2006). Generation of a functional mammary gland from a single stem cell. Nature, 439, 84-88.

248. Coclet, J., Foureau, F., Ketelbant, P., Galand, P., \& Dumont, J. E. (1989). Cell population kinetics in dog and human adult thyroid. Clinical Endocrinology, 31, 655-665.

249. Doll, R., Peto, R., Boreham, J., \& Sutherland, I. (2004). Mortality in relation to smoking: 50 years' observations on male British doctors. BMJ, 328, 1519 .

250. Glickman, M. S., \& Sawyers, C. L. (2012). Converting cancer therapies into cures: Lessons from infectious diseases. Cell, 148, 1089-1098.

251. Basanta, D., Gatenby, R. A., \& Anderson, A. R. (2012). Exploiting evolution to treat drug resistance: Combination therapy and the double bind. Molecular Pharmaceutics, 9, 914-921.

252. Bernards, R. (2012). A missing link in genotype-directed cancer therapy. Cell, 151, 465-468. 